\section{El castillo de San Romualdo (San Fernando, Cádiz). Aproximación estratigráfica y evolución constructiva}

\section{The castle of San Romualdo (San Fernando, Cádiz). Stratigraphic approach and building evolution}

Raquel M. Utrera Burgal

Arqueóloga*

Miguel Ángel Tabales Rodríguez

Dep. de Construcciones Arquitectónicas 2. Universidad de Sevilla**

\section{Resumen}

Presentamos en este artículo los resultados de nuestra investigación arqueológica en el castillo de San Romualdo, el edificio más emblemático de la ciudad de San Fernando y fortaleza defensiva ligada al control del acceso a Cádiz. El análisis estratigráfico de alzados ha permitido conocer la evolución constructiva del edificio, desde sus orígenes hasta la actualidad. Hasta ahora los estudios confirman las conclusiones en cuanto a su datación presentadas en el año $2003^{1}$, es decir, el castillo, tal y como hoy lo conocemos, es una construcción medieval cristiana realizada durante la segunda mitad del siglo XIII, con mano de obra mudéjar y con materiales reutilizados de una edificación anterior.

Palabras clave: Castillo de San Romualdo; análisis estratigráfico; construcción medieval; procesos constructivos.

\begin{abstract}
This article shows the results of the archaeological research carried out in the castle of San Romualdo, the most emblematic building of the city of San Fernando and a defensive fortress tied to the control access of Cádiz. The standing building recording has enabled to know the building evolution from its origins until the present. Studies have hitherto confirmed the chronological conclusions already proposed in 2003. That is, the current castle is a medieval Christian building erected in the second half of the 13th century thanks to Mudejar workers and materials reused from a previous building.
\end{abstract}

Keywords: Castle of San Romualdo; stratigraphic analysis; medieval building; building processes.

*raquelmub@gmail.com

**tabales@us.es

${ }^{1}$ El castillo de San Romualdo fue expropiado a finales de los años 90 y es partir de esa fecha cuando se inician las actuaciones arqueológicas, en concreto, desde el año 2000, y siempre enmarcadas en diferentes campañas de apoyo a la restauración del edificio. El análisis estratigráfico de los alzados del castillo se inició en el año 2003, con una primera aproximación arqueológica en la que se estudiaron tres lienzos. Las conclusiones que presentamos en este artículo son el resultado de una intervención arqueológica realizada en los años 2006 y 2007, que comprendió una lectura de paramentos y es simplemente la continuación del análisis comenzado en el año 2003, completado con la lectura del resto de alzados y complementado por una intervención en subsuelo realizada tanto en la planta baja del edificio, como en la primera planta, donde el refuerzo de muros y bóvedas requirió el vaciado de los rellenos del trasdós de estas. Los estudios realizados en el castillo han sido coordinados por don Antonio Sáez Espligares (Museo Histórico Municipal de San Fernando, Cádiz).

\section{DESCRIPCIÓN}

El Castillo de San Romualdo se encuentra en San Fernando (Cádiz), muy próximo al Puente Suazo. Dicho puente constituye el único punto de comunicación terrestre entre el continente y la ciudad de Cádiz desde época antigua ${ }^{2}$, por lo que la situación del castillo no es casual, obedeciendo a cuestiones estratégicas. Esta relación influyó en la denominación del edificio desde época medieval como Castillo de la Puente, más tarde conocido como Castillo de Suazo o Castillo de León (en relación a los diferentes señores propietarios del edificio), hasta su denominación actual, Castillo de San Romualdo, que aparece en el siglo XIX ${ }^{3}$.

Construido en una explanada, es un edificio de planta rectangular (Fig. 1) con cuatro torres en las esquinas, las dos occidentales ( $\mathrm{T} 1$ y T6) de mayor tamaño, y con una torre central en cada uno de los flancos (excepto el lienzo oriental donde no se conserva). En sus inicios, estuvo rodeado de un foso, ahora colmatado (Fig. 2). Tiene un patio de armas central, rectangular, con unas medidas aproximadas de $33 \times 15 \mathrm{~m}$. Está delimitado por cuatro naves, entre ellas la más alta es la occidental. Cada una de las naves está formada por una serie de habitaciones abovedadas, en la planta baja existen veintiséis. La planta superior queda constituida por una terraza transitable desde la que se accede al interior de tres torres que aún conservan parte de su alzado original. Los materiales empleados en su construcción fueron el cajón de tapial (en lienzos y torres), la piedra (sillares en torres y forros de refuerzo en los muros) y ladrillo (empleado fundamentalmente como cadena del tapial en vanos y torres y sobre todo en la ejecución del interior del edificio, arcos y bóvedas).

En 1931 fue declarado «Monumento Histórico Artístico" siendo hoy día un Bien De Interés Cultural.

\section{HIPÓTESIS SOBRE SU ORIGEN}

Sobre el origen del edificio se han expuesto varias teorías, las que lo sitúan de forma más remota en el tiempo lo identifican con una fortaleza tartésica, el Arx Gerontis, destruida por los fenicios hacia el siglo $\mathrm{V}$ a.C. y que guardaría una relación tipológica con los hithilani o palacios fortificados asirios (Corzo Sánchez, 1984), con un

\footnotetext{
2 El estudio de estratigrafía vertical realizado en el año 2006 por Miguel Ángel Tabales y Juan Miguel Pajuelo Sáez revela que aunque el puente actual es una construcción realizada en los siglos XVI-XVII, se apoya en los restos del antiguo puente-acueducto romano, con una cronología relativa de los siglos I y II d.C. ${ }^{3}$ Mosig (Mosig 2005, p. 42) indica que el nombre actual se utiliza por primera vez en el Diccionario Geográfico Estadístico e Histórico de España elaborado por Pascual Madoz, y que posiblemente se debió a un error tipográfico o interpretativo que confundió «El Castillo de San Fernando» por «El Castillo de San Romualdo».
} 


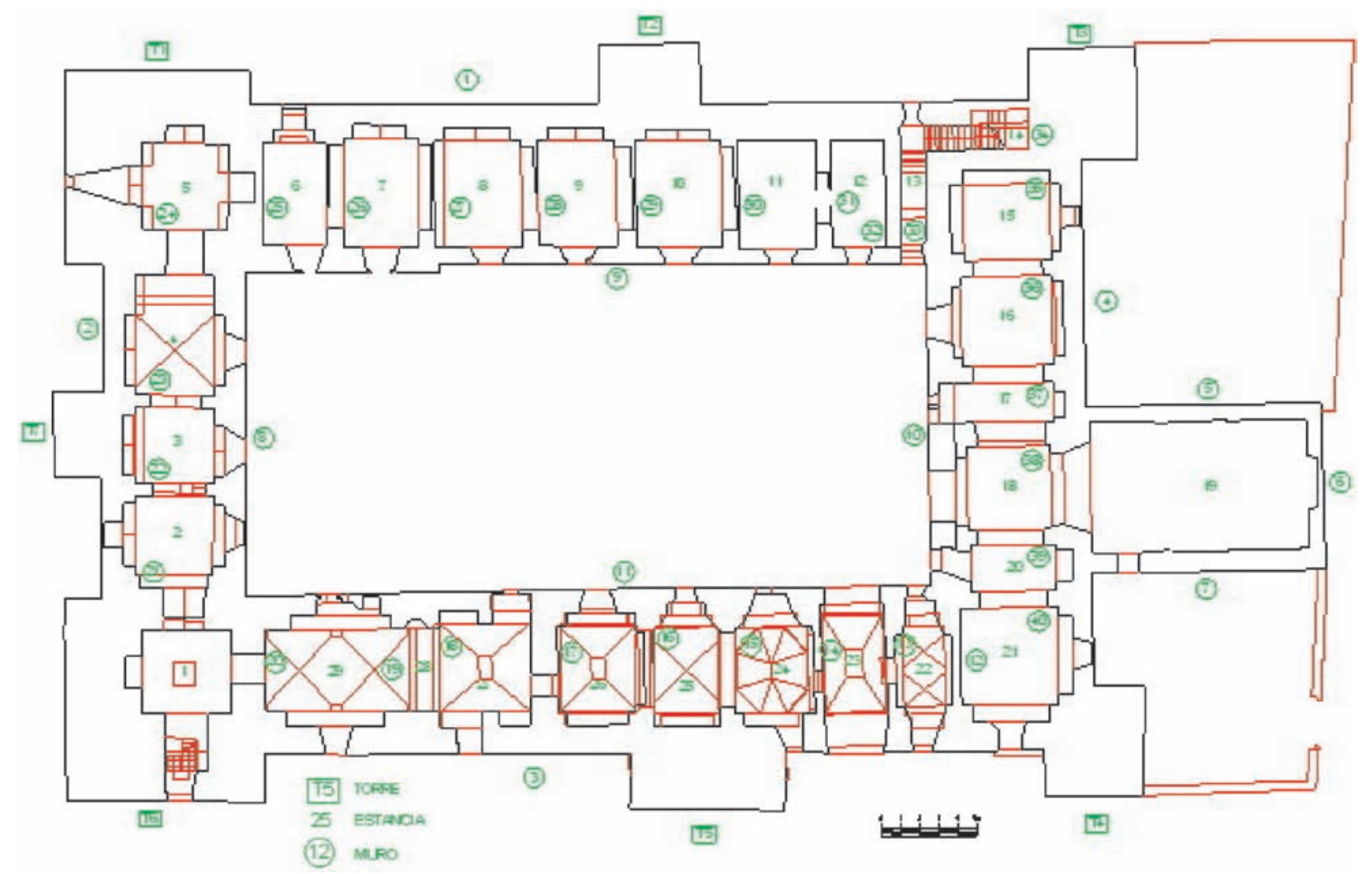

Fig. 1. Planta baja del castillo con la identificación de estancias, muros y torres

castellum de época romana o con una fortaleza bizantina. Sin embargo, ninguna de estas teorías ha podido ser confirmada por la arqueología hasta el momento.

La hipótesis más extendida es la expuesta por Torres Balbás, quien indicaba la posibilidad de que hubiera sido construido copiando un ribat islámico por alarifes musulmanes, pero ya bajo dominio cristiano, a principios del siglo XIV (en concreto la terminología que usa en su argumentación es: «un ribat cristiano»). El autor se basa en las comparaciones realizadas con el ribat de Susa en

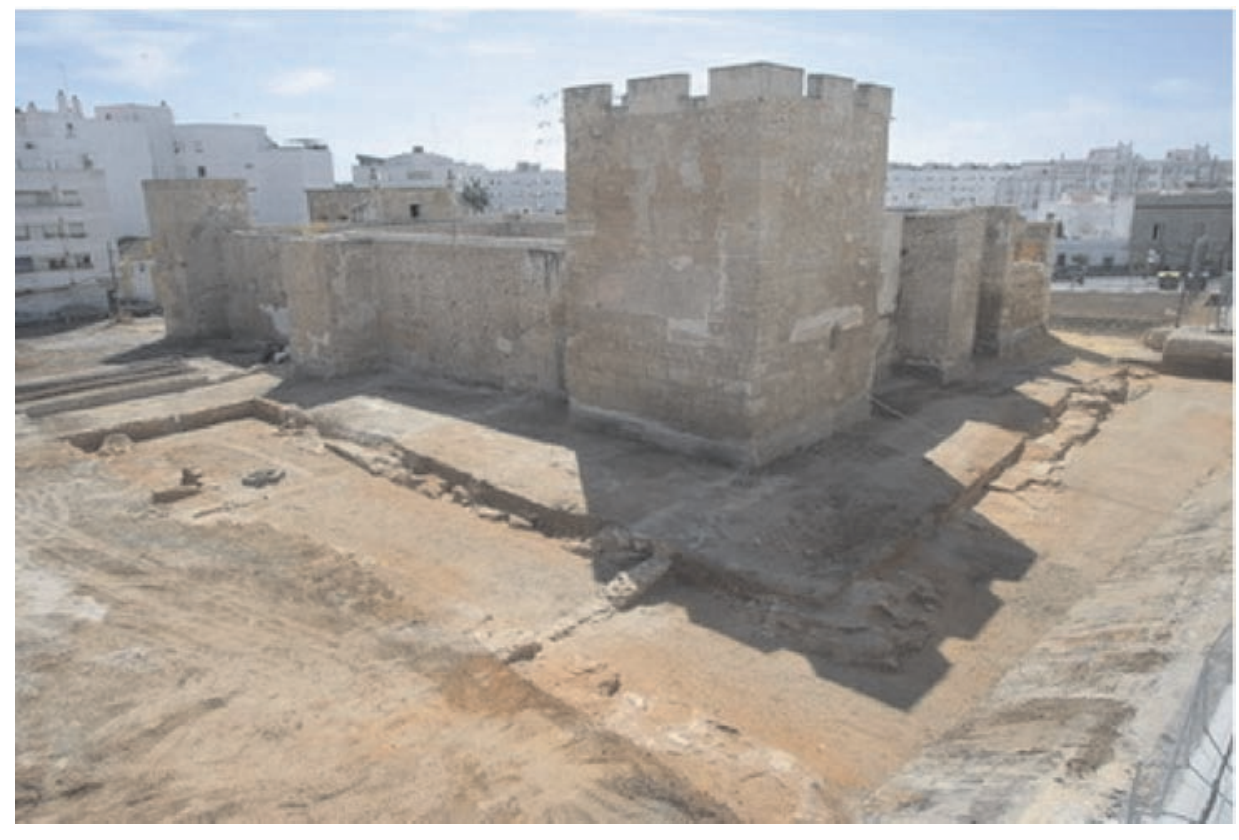

Fig. 2. Vista del castillo desde el oeste con la obra de delimitación del foso realizada por J. J. Cantillo 


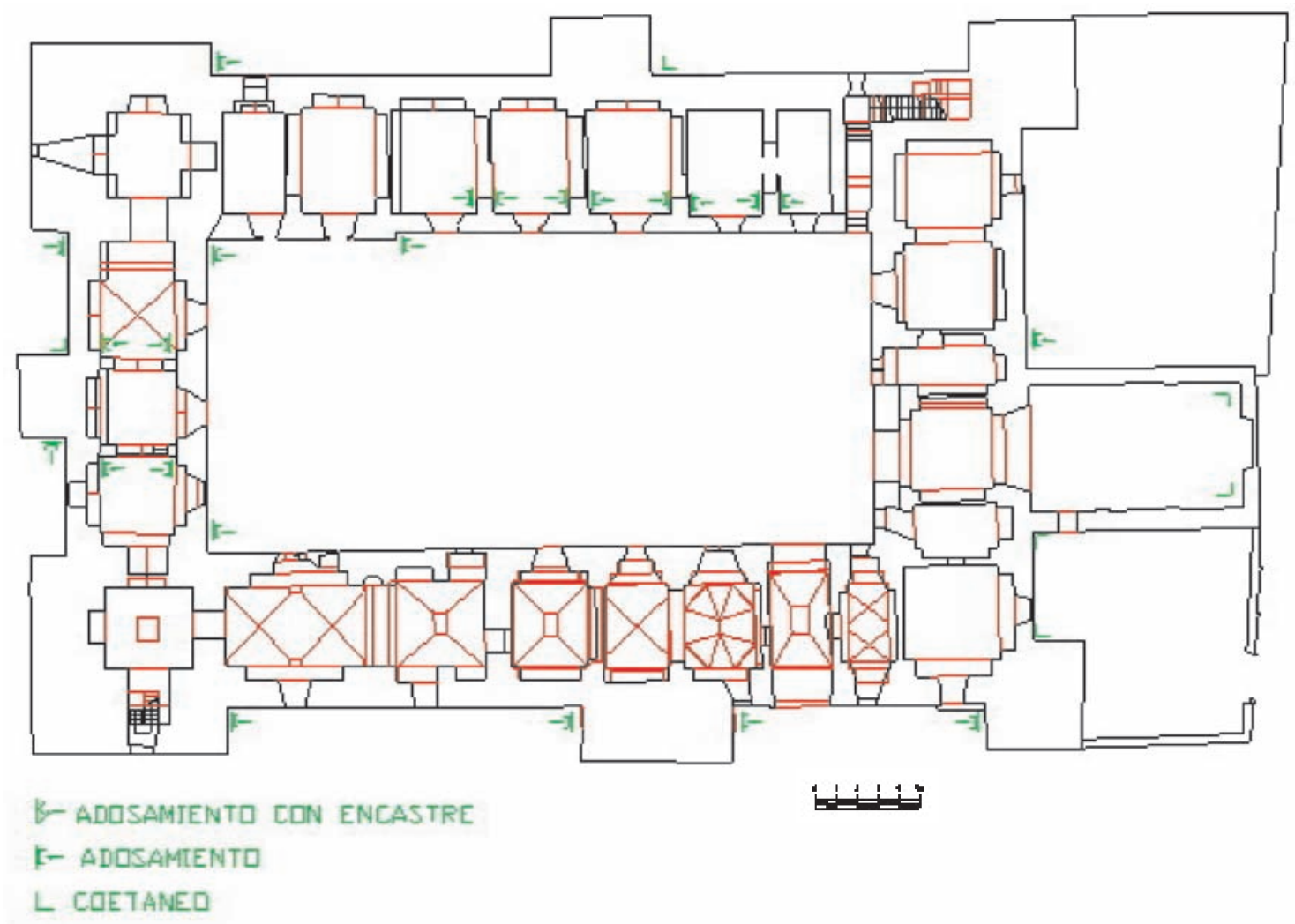

Fig. 3. Sistemas de adosamientos

Túnez, además apunta la posibilidad de que se construyera aprovechando los restos de un ribat preexistente en la zona y considera que es mudéjar basándose en la presencia de bóvedas de aristas seguidas y esquifadas sobre trompas que no se encuentran en edificios andaluces antes del siglo XIII (Torres Balbás, 1950, pp. 210-213). Fierro Cubiella propone que se trata de una fortificación costera defensiva hispanomusulmana, edificada frente a los ataques normandos del siglo IX ${ }^{4}$, aprovechada y reconstruida posteriormente. Indica que no puede ser un ribat, ya que el término ribat no aparece en la toponimia de la zona ni existen referencias bibliográficas al respecto y lo considera incompatible históricamente. Por el contrario, le asigna una función defensiva, apoyándose en textos hispanomusulmanes que lo refieren como castillo y determina como parte más antigua la del área norte en base a las bóvedas de cañón que caracterizan este ala (Fierro Cubiella, 1991, pp. 38-44). Este autor sigue la hipótesis del «Fuerte Cuadrado» planteada por Eslava Galán aunque para este último el castillo fue realizado por alarifes musulmanes en suelo cristiano (Eslava Galán, 1985, p. 48).

\footnotetext{
${ }^{4}$ En concreto lo sitúa entre el año 844, fecha de las razzias, y el 852, final del
} Emirato de Abderramán (Fierro Cubiella, 1991, p. 55).
La historiografía tradicional otorga la autoría de la construcción del castillo a Alfonso X, sobre todo basándose en los textos de Pascual Madoz y Adolfo de Castro (Mosig Pérez, 2005, p. 60). Adolfo de Castro indica que el Castillo se construyó para defensa del puente (Castro Rossi, 1858, p. 310).

Sin embargo, la primera referencia escrita al Castillo de la Puente de Cádiz no aparece hasta $1335^{5}$, en un documento que recoge la donación de Alfonso XI a Gonzalo Díaz de Sevilla.

Como hemos visto, la controversia sobre los orígenes del castillo hacía fundamental el análisis estratigráfico de los diferentes alzados para su futura puesta en valor.

\section{SECUENCIA ESTRATIGRÁFICA}

El análisis confirma la existencia de nueve procesos, relacionados con las etapas históricas más relevantes del edificio $^{6}$ (Fig. 4):

\footnotetext{
${ }^{5}$ Según Torres Balbás en 1328 (Torres Balbás, 1950, p. 213)

6 La metodología utilizada es la planteada por Miguel Ángel Tabales en edificaciones históricas (Tabales Rodríguez, 2002). Siguiendo el sistema Harris aunque con ciertas puntualizaciones, en síntesis consiste es una estrategia de intervención global que comprende un acercamiento inicial al edificio a través de comprobaciones tipológicas y estructurales para llegar a una hipótesis evolutiva
} 
PROCESO 1

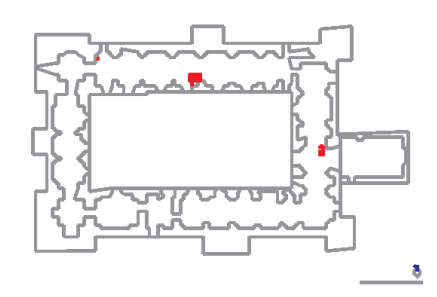

PROCESO 3. FASE 2

(Ca.1260)

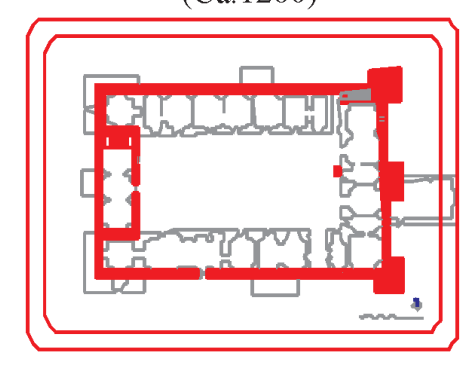

PROCESO 3. FASE 5

(Ca.1260)

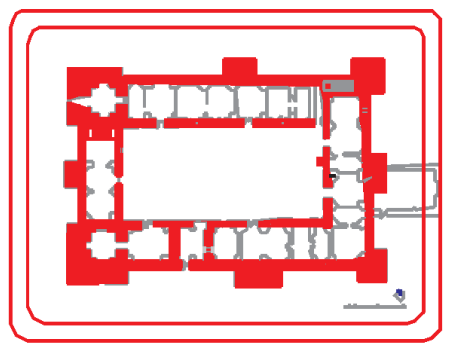

PROCESO 5.

(Reconstrucción bajomedieval)

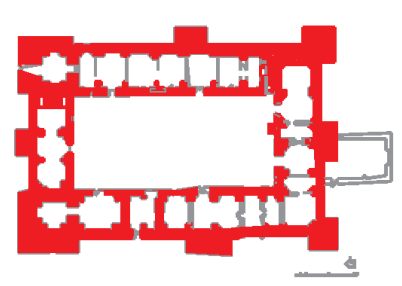

PROCESO 7.

(1769-1846)

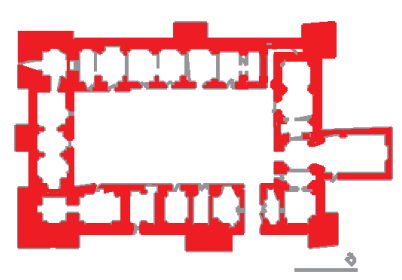

PROCESO 2

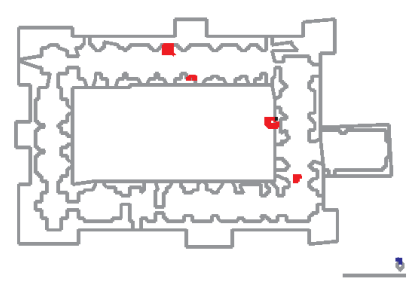

PROCESO 3. FASE 3

(Ca. 1260)

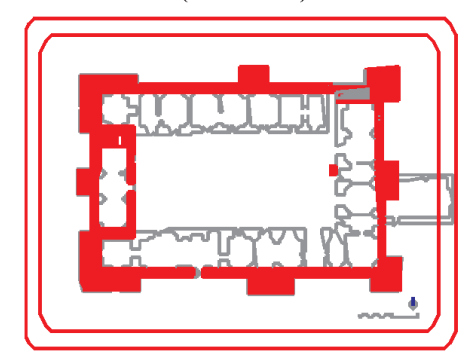

PROCESO 3. FASE 6

(Ca.1260)

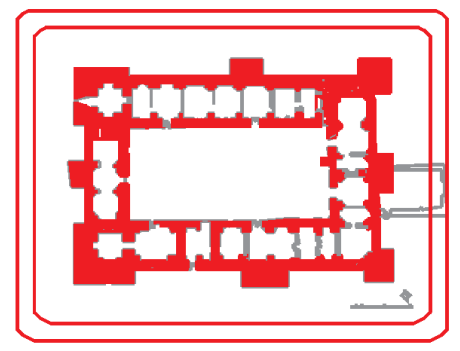

PROCESO 6. FASE I. (Siglo XVII-1736)

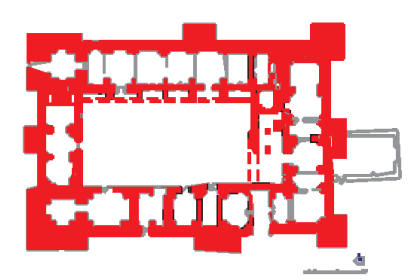

PROCESO 3. FASE 1

(Ca.1260)

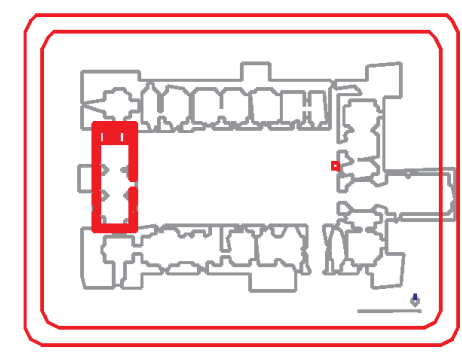

PROCESO 3. FASE 4

(Ca.1260)

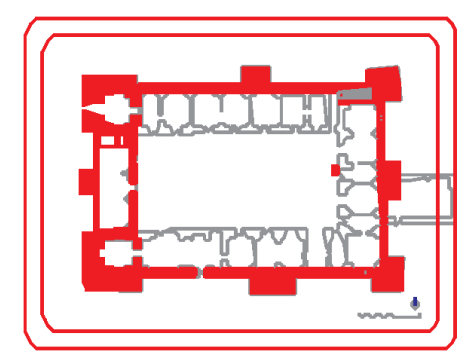

PROCESO 4.

(Destrucción bajomedieval)

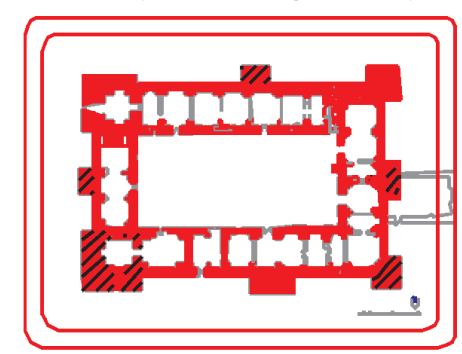

PROCESO 6. FASE II. (1736-1769)

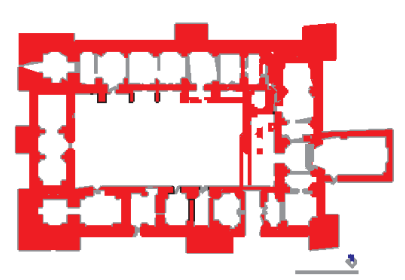




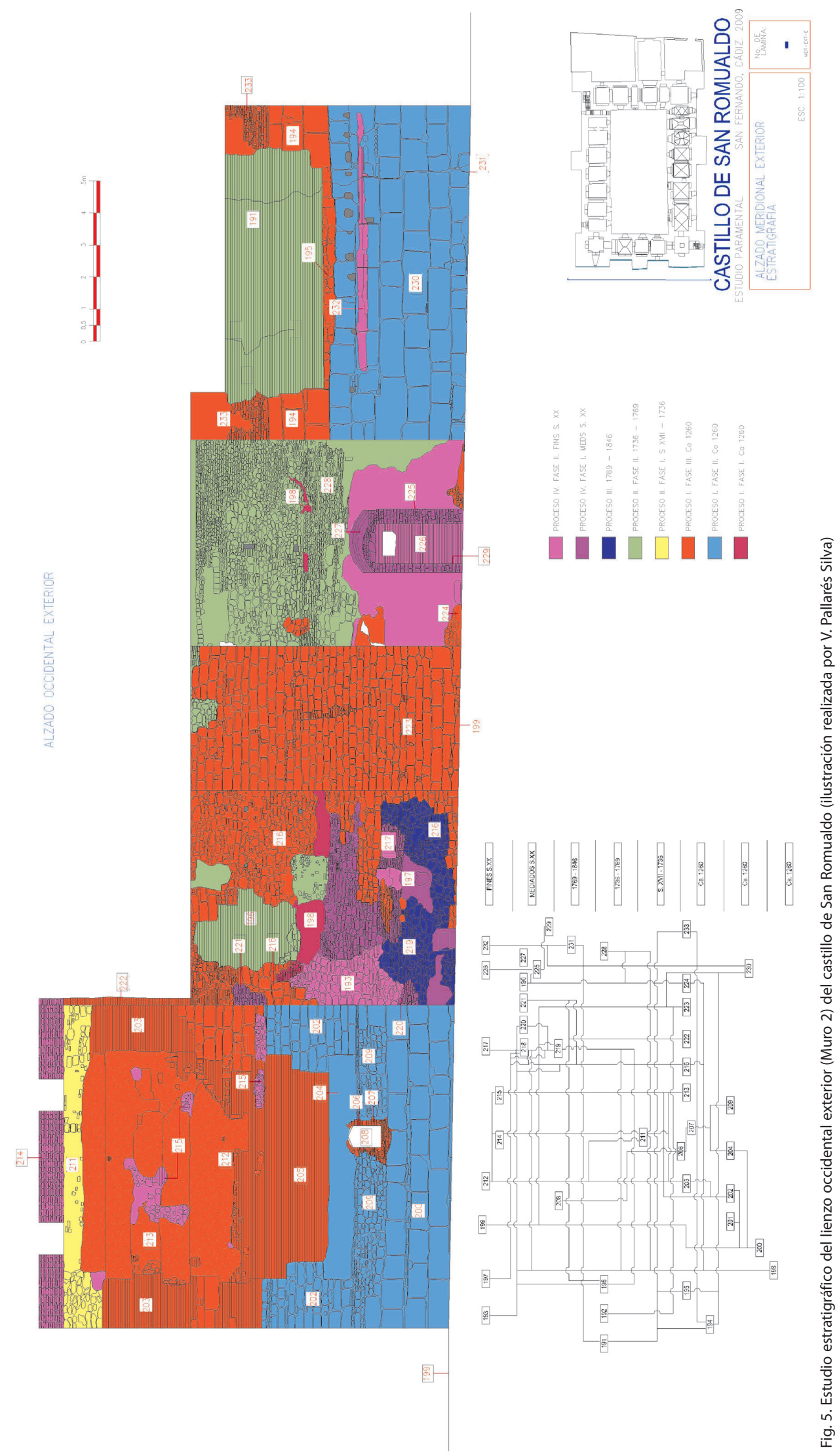




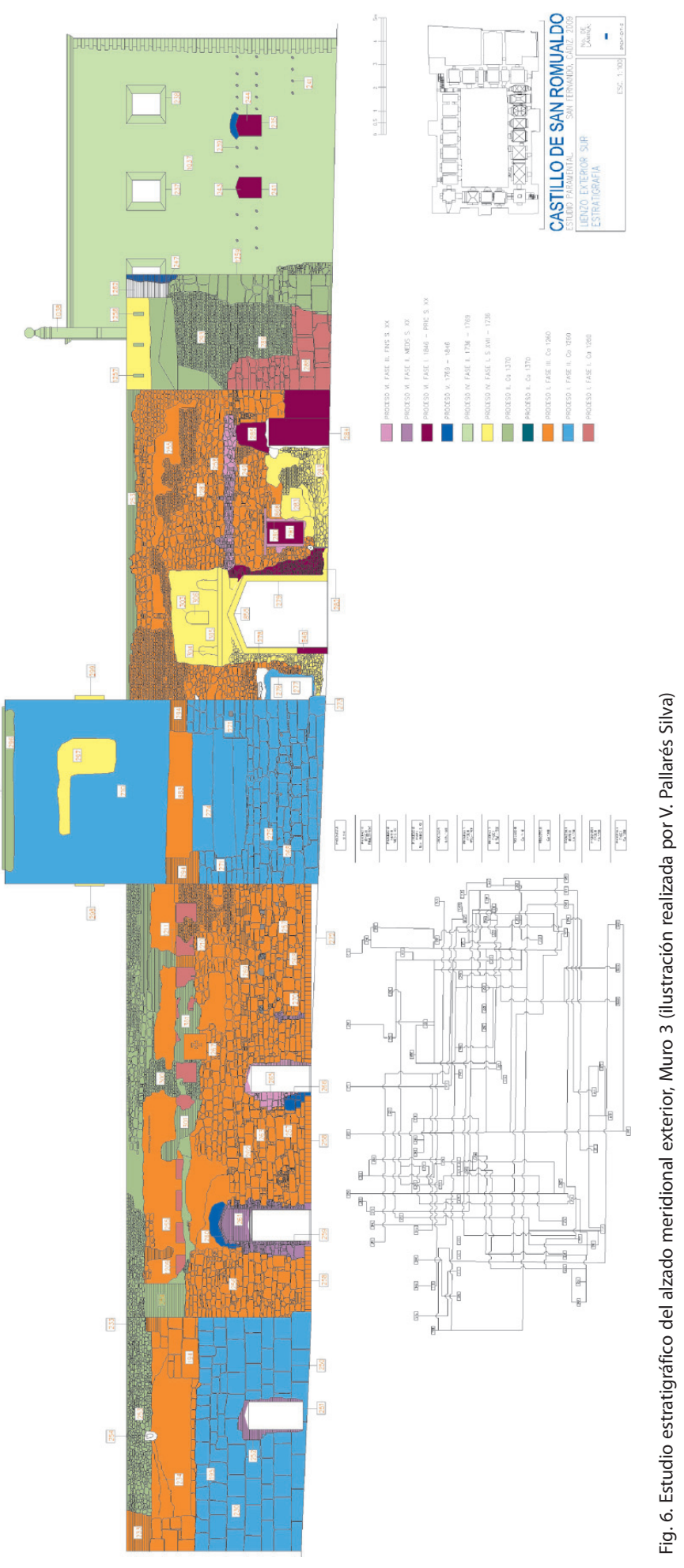




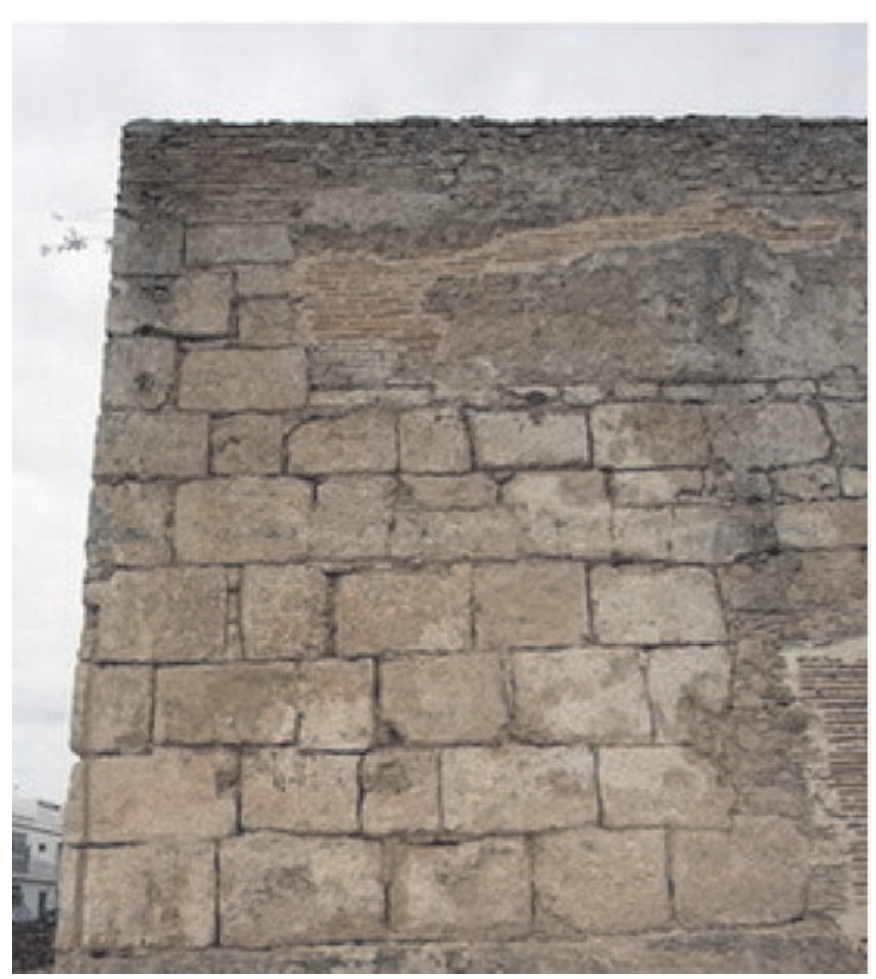

Fig. 7. Sillares reutilizados en la torre 6.

Proceso I: época romana. En esta época, las estructuras aparecidas en el interior del edificio son muy escasas y parecen corresponder a restos funerarios que podrían relacionarse con una necrópolis tardo-romana (siglos IV$\mathrm{V})^{7}$, aunque sólo nuevas intervenciones en los exteriores de la fortaleza (sobre todo en la zona septentrional) podrían aclarar estos momentos. Con respecto a la hipótesis de una edificación previa, no hay evidencias en cuanto al estudio de paramentos se refiere. Sin embargo, las dimensiones y módulos de los sillares calcáreos (con medidas moduladas a partir del codo romano e inusuales en época almohade ${ }^{8}$ ) utilizados en la base, escarpa y alzados de las torres angulares (Fig. 7) hacen pensar que son materiales produc-

inicial y un análisis de paramentos posterior que comprende una lectura estratigráfica, tipológica y constructiva del lienzo (las dos últimas realizadas por Amparo Graciani, Antonio Melo Montero y Antonio Calama), apoyado por la intervención de subsuelo y todo ello a través de un minucioso sistema de registro de datos. El estudio se efectuó sobre los dieciséis alzados principales del edificio, estos son: cuatro lienzos exteriores de la fachada, cuatro que conforman el patio de armas y dos en cada una de las crujías interiores, en número total de ocho.

${ }^{7}$ Esta cronología se basa en la documentación de subsuelo realizada en el ala norte durante esta intervención, sin embargo las actuaciones arqueológicas desarrolladas en la zona extramuros del Castillo en los años 2000-2002 confirmaron la presencia de una notable número de materiales romanos con una cronología para la presencia romana en el Castillo situada «entre momentos tardorrepublicanos cercanos al principado de Augusto y los comienzos del Bajo Imperio». Los autores no descartan que el Castillo tuviera su origen en la Antigüedad (Sáez Romero et al., 2004, pp.108 y 116).

8 Sogas: 0.56 a $1.10 \mathrm{~m}$, tizones: 0.60 a $0.70 \mathrm{~m}$, alturas: 0.58 a $0.72 \mathrm{~m}$. to del acarreo de una edificación anterior ya destruida y situada en las inmediaciones del castillo'. En todo caso, esperamos que los trabajos futuros, arrojen más luz sobre este aspecto.

Proceso II: ocupación islámica, probablemente almohade. Se han detectado estructuras anteriores al castillo, como un pozo situado al este del patio de armas ${ }^{10}$ o muros en la nave oriental, pero se desconoce aún la función que tendría la zona en estos momentos ${ }^{11}$. Como se ha indicado anteriormente, algunos autores abogan por el origen musulmán del edificio. Hasta ahora, nuestros estudios de subsuelo no han probado una cronología anterior al siglo $\mathrm{XIII}^{12}$ y aunque no la descartamos, el análisis de alzados parece confirmar un origen cristiano.

Proceso III: en este proceso se resume la construcción del castillo, que situamos en la segunda mitad del siglo XIII, con posterioridad al segundo repartimiento conocido de Cádiz (que tuvo lugar en 1264) durante el reinado de Alfonso X, quizás por parte de una orden militar $^{13}$ y con mano de obra mudéjar procedente de Jerez de la Frontera. Compartimos por tanto la hipótesis que en 1934 apuntó Romero de Torres. Con respecto a la sugerente idea del ribat reutilizado, nos mostramos escépticos.

Por su importancia y relativa facilidad de defensa, como sucedería con Jerez, Arcos y el Puerto de Santa

\footnotetext{
${ }^{9}$ Estos materiales podrían pertenecer al puente-acueducto situado en el Puente Suazo, o a una construcción defensiva (que cómo hemos mencionado antes no tiene indicios arqueológicos) que defendiera dicho puente, o incluso a la denominada Iglesia de San Bitro, de época tardoromana que citan las fuentes musulmanas y que se situaría cercana al emplazamiento del castillo (Torres Balbás, 1950, p. 202).

${ }^{10}$ Este pozo es anterior a la fase $\mathrm{V}$ del tercer proceso en el que se erige el castillo, proceso cuyas fases hasta ahora identificamos dentro de un mismo momento constructivo, sin embargo su situación no sería incompatible durante las dos primeras fases, si las futuras intervenciones de subsuelo demuestran que estas corresponden a una cronología anterior.

${ }^{11}$ Antonio Sáez Espligares y Antonio Sáez Romero hacen referencia a que la aparición de silos agrícolas y fosas domésticas en el término de San Fernando confirmaría una proliferación de alquerías en el área extra-urbana de la isla de Cádiz (Saez y Sáez, 2005, p. 11).

${ }^{12}$ En uno de los sondeos realizados en el año 2002 en el ala septentrional se encontró un silo datado en época islámica tardía. Según los autores, este silo se podría asociar o bien a una alquería o bien se ubicó en el "recinto murario del castillo en un momento en el que este no disponía aún de naves» (Sáez y Sáez, 2009). Este último caso podría identificarse con el primer edificio con el cerco exterior almenado que describiremos en el proceso III (fases I y II).

${ }^{13}$ No hay que olvidar que la conquista del Sur del país fue posible por el papel que ejercieron las órdenes militares y por el apoyo generado por la Conquista del Reino de Sevilla por San Fernando en 1248 y que tanto Alfonso X como Sancho IV intentaron asociar las órdenes militares al proceso de repoblación y organización de esta zona (Bahía de Cádiz) fronteriza, terrestre y marítima. Así en 1279 la Orden de Santa María de España recibió por parte de Alfonso X las villas y los castillos de Medina Sidonia y Alcalá de los Gazules.
} 
María, Cádiz fue repoblada mediante el sistema que se había impuesto en Castilla en el siglo XIII, es decir, mediante una serie de repartimientos mixtos entre el rey por medio de concejos municipales y ciertas colectividades o personas jurídicas nobiliario eclesiásticas (órdenes militares y dignidades religiosas $)^{14}$. Cuando Cádiz fue conquistada, Alfonso X mandó hacer su reedificación (Horozco, 2001, p. 150). El entorno de la Isla de San Fernando se integraría en el alfoz de Cádiz, en el término que se le asignaba en el repartimiento. Consciente de la importancia estratégica del lugar, cercano al puente-acueducto romano que controlaba el acceso a Cádiz, Alfonso X, como haría con el Castillo de Rota y posteriormente en 1281 con la Puebla de Santa María del Puerto, durante el proceso de la segunda repoblación de Cádiz, dotaría de un concejo propio a la zona, pasando a llamarse el Logar de la Puente, para cuya defensa se llevaría a cabo la construcción del castillo.

La población del lugar tras la repoblación debió ser escasa y resulta poco probable que la mano de obra utilizada para esta construcción fuera local, ya que tras la sublevación de 1264, Alfonso X, que habría modificado su política previa de favorecer la permanencia de amplios colectivos de mudéjares mediante la concesión de privilegios y pactos, habría procedido a su expulsión. De hecho, según González Jiménez (1983, p. 17), tras la expulsión de 1264 no existen vestigios de población mudéjar en Cádiz ni en El Puerto de Santa María. Parece posible que el edificio se construyera con mano de obra procedente de Jerez de la Frontera, ya que según este autor, tras la expulsión allí sí seguiría existiendo un importante núcleo mudéjar. En cualquier caso, debía haberse realizado esta primera obra entre 1264 y 1300 , pues en esta última fecha ya se habían extinguido los mudéjares de Jerez. Probablemente se tratara de una iglesia fortificada de planta rectangular, reforzada en sus ángulos con torres y dotada de un foso perimetral.

La construcción, que debió estar planificada desde un primer momento, se realizó en varias fases como consecuencia del desarrollo progresivo de la obra:

\section{Proceso III. Fase I: Creación del edificio primigenio.}

Dentro del proceso constructivo del castillo, la primera fase la constituye la creación con muros de cajones de tapial de una nave en la zona occidental, de tamaño más reducido que el que podemos contemplar actualmente. Este primer edificio, disponía de un almenado dotado de

${ }^{14}$ No hay constancia documental a quién se asignó el Logar de la Puente. aspilleras, conservadas en su lienzo occidental y meridional (Figs. 8 y 10) Las aspilleras son alargadas y estrechas en el lienzo sur y rectangulares en el oeste (Fig. 8). Algunos de estos merlones conservan restos de dibujos en carboncillo y grabados incisos en el enlucido del tapial, destacando la representación de forma esquemática de un alzado en el que se pueden apreciar muros coronados por almenas y torres (Fig. 9), como si se tratara de un plano del proceso de obra. El parapeto mide medio metro de ancho y los merlones entre $0,94 \mathrm{~m}$ y $1 \mathrm{~m}$ de largo, con una distancia entre ellos de $0,48 \mathrm{~m}$ y $0,5 \mathrm{~m}$. Desde la cubierta no se puede apreciar el nivel de suelo original del paso de ronda, que se encuentra cubierto por la construcción de las bóvedas interiores del edificio. Esta nave, más antigua, desde un principio se erigió más alta para dominar visualmente el cerco y el interior del recinto fortificado. Probablemente la construcción del foso que rodea al castillo, se inicie en estos momentos ${ }^{15}$. Con respecto al foso, los sondeos realizados en el año 2000 señalan que se trata de una cava seca en artesa y no inundable, abierta a una distancia de siete metros de los paramentos verticales de las torres de flanqueo y cuya escarpa presenta un plano inclinado de $45^{\circ}$ con respecto a la vertical de la muralla (Torremocha et al., 2000, pp. 26 y 31).

Proceso III. Fase II: Erección del cerco exterior almenado realizado en cajones de tapial de tierra y cal compactadas (Fig. 14) que servirá para proteger la edificación, con la construcción de dos torres en el frente oriental, más cercano al Puente Suazo, antiguo puente-acueducto (arruinado y perdida su función primigenia) sobre el que se acondicionaría un paso de madera. El hecho de que situemos ambas torres en esta fase se debe a la aparición en la esquina noreste, junto a la escalera, del frente oeste de la torre 3. No se ha podido constatar esta evidencia en la torre 4, pero ambas tienen las mismas características y no sería lógico suponer que sólo fuera una torre la que defendiera esta zona más conflictiva. Posiblemente la torre de flanqueo central también se construyera en esta fase y probablemente existiera en este frente una puerta de acceso al recinto protegida por estas torres. Sin embargo, si existió es imposible de documentar, ya que la obra de la capilla del Rosario en el siglo XVIII acabó con todo el registro en esta

\footnotetext{
15 En las escasas intervenciones realizadas en el foso, se documentó la presencia de cerámica romana en los rellenos de colmatación de los siglos XIV y XV, aumentando ésta en relación a su proximidad al fondo por lo que sus autores no desechan una cronología anterior, aunque de momento las conclusiones descartan la interpretación del Castillo como obra ex novo romana (Sáez et al., 2004, pp. 109 y 110).
} 

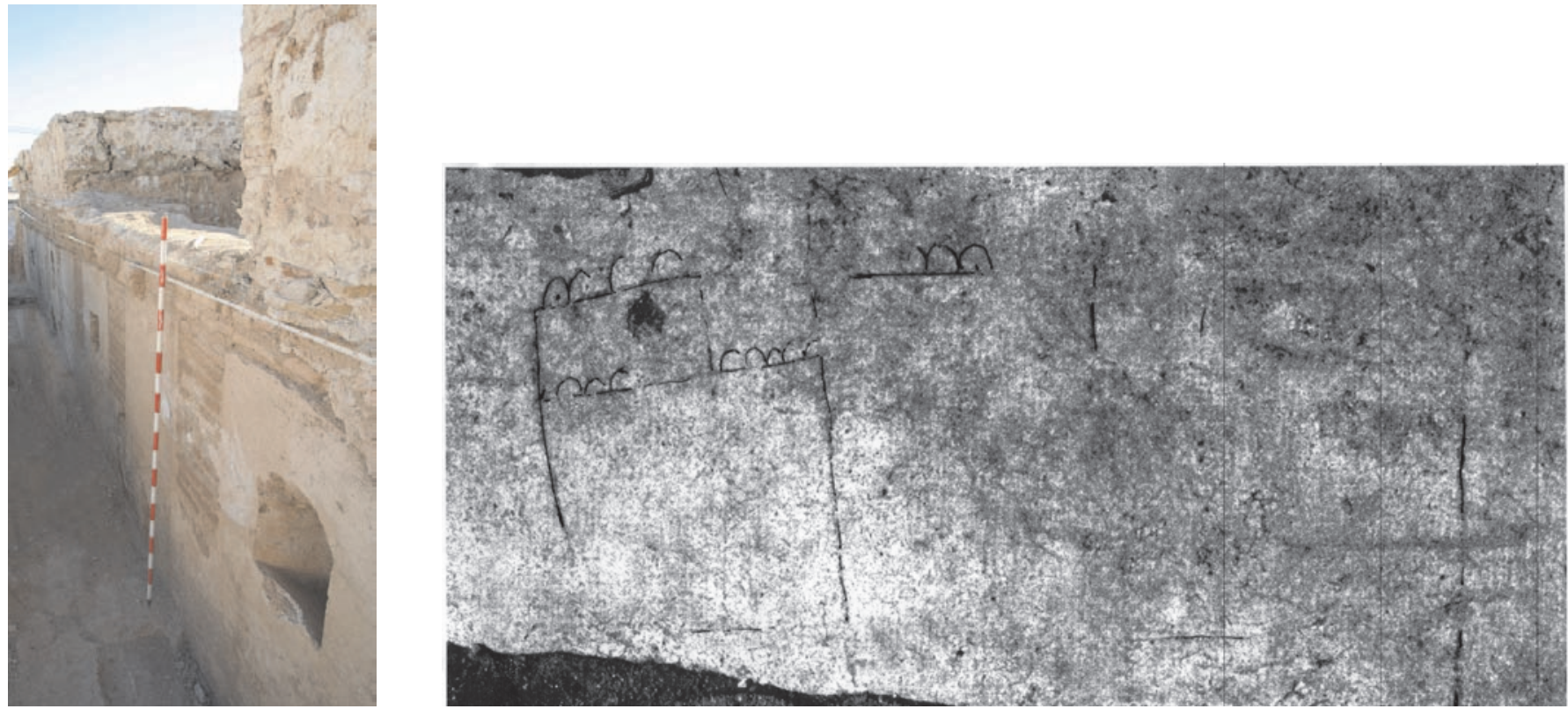

Figs. 8 y 9. Almenado occidental de edificio primigenio con detalle de aspillera rectangular y detalle de dibujo en un merlón representando torres y murallas almenadas

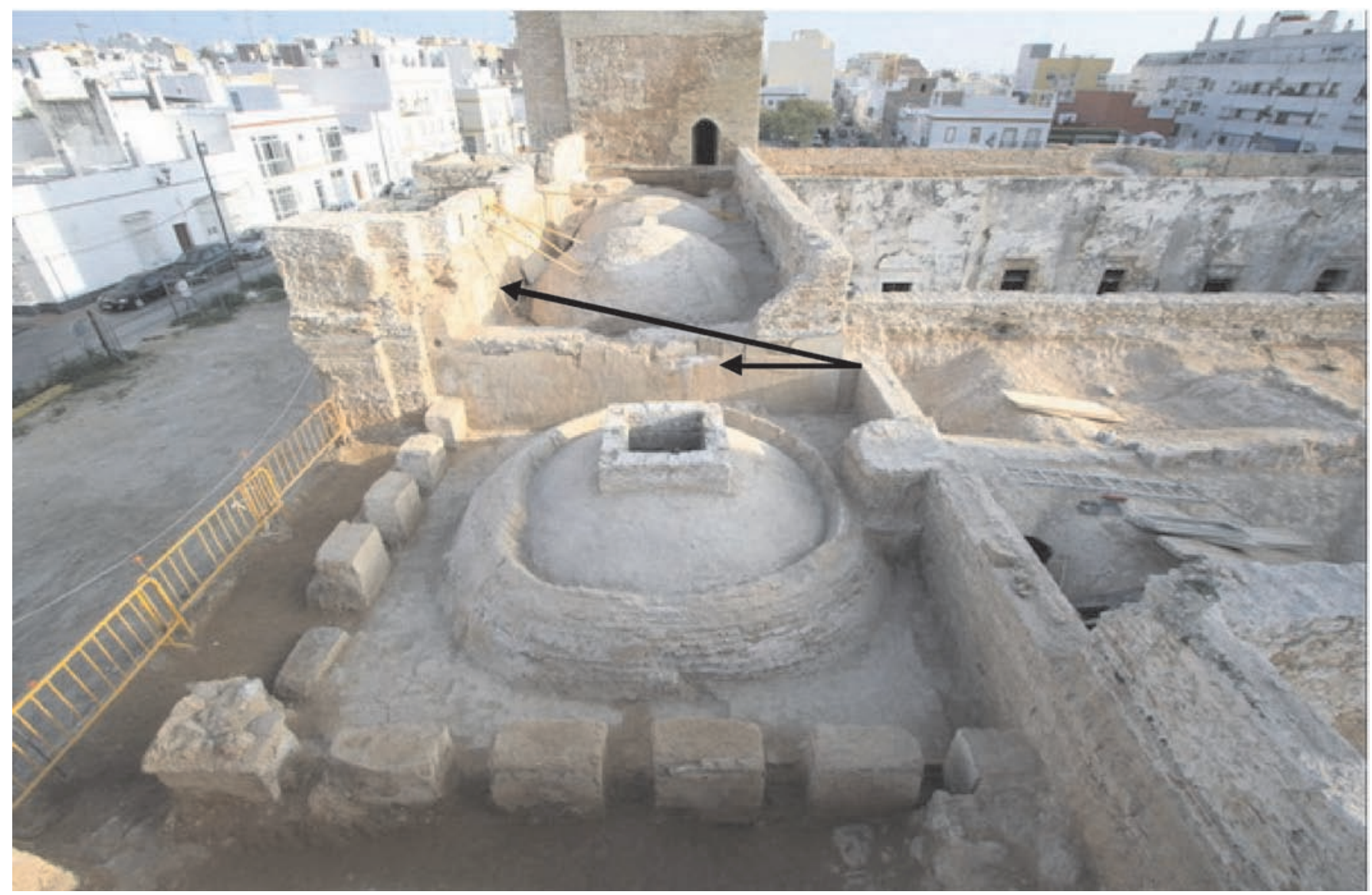

Fig.10. Almenado en torre 6, al fondo localización del alzado sur y oeste de la nave original

zona. Sí se ha conservado completa la escalera de acceso original al adarve en la esquina nororiental.

En la cubierta del edificio se pudo registrar parte del almenado en la esquina suroeste (Torre 6) y en la zona norte, aunque se mantiene en la mayor parte del edificio (se puede observar en los alzados exteriores) a unos dos 


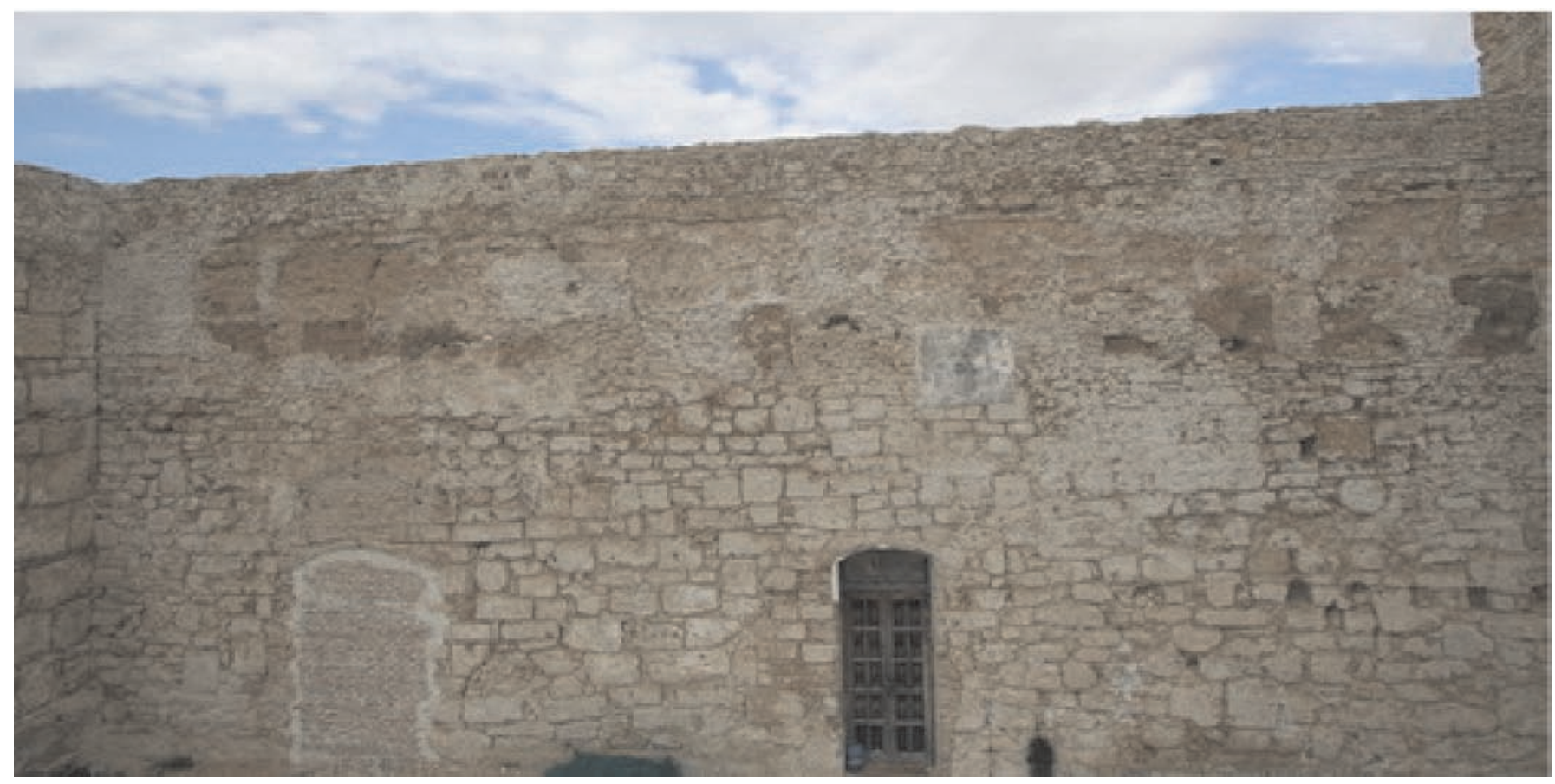

Fig. 11. Lienzo meridional en el que se aprecia el almenado del primer cerco
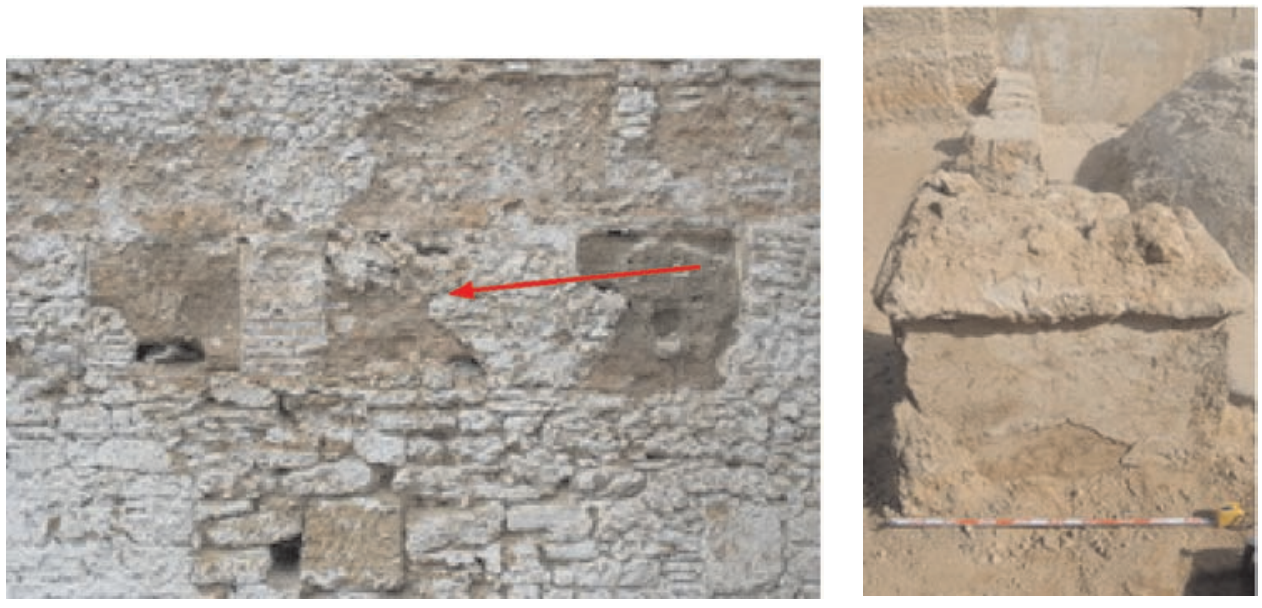

Figuras 12 y 13. Detalle de la merlatura anterior (con aspilleras) y merlón con remate a cuatro aguas (T6)

metros bajo el parapeto actual (Figs. 11 y 12). Uno de estos merlones aún conserva la albardilla a cuatro aguas realizada en piedra (Fig. 13). Las aspilleras abiertas en el parapeto (Fig. 11) de esta muralla son alternas y rectangulares y hay que señalar que en la esquina suroeste no existen, porque esta zona se encontraba ya defendida por la nave original más elevada. En esta fase se abriría en el lienzo sur la puerta para acceder al castillo documentada en el año 2003 y parcialmente desaparecida, con dovelas pétreas y rosca rebajada. Esta puerta es referida durante el ataque angloholandés como menuda y forrada con hierro (Abreu, 1866).
Proceso III. Fase III: En estos momentos se inicia la construcción de las torres que se adosan al cerco. Todas, excepto la torre 7 (y en menor proporción la torre 3), se construyen sobre una base de sillares de grandes dimensiones (probablemente de acarreo de una construcción anterior), isódomos en las torres angulares, con un aparejo predominante a soga (aunque en la torre 4 se aprecian sillares dispuestos conforme a un aparejo diatónico de tipo califal) y se elevan con cajones de tapial encadenado con sillarejo, hasta el nivel del adarve del cerco. Las torres 5 y 6 en el lienzo sur, presentan escarpa, evidenciando un declive topográfico en el momento de su construcción (a una cota 


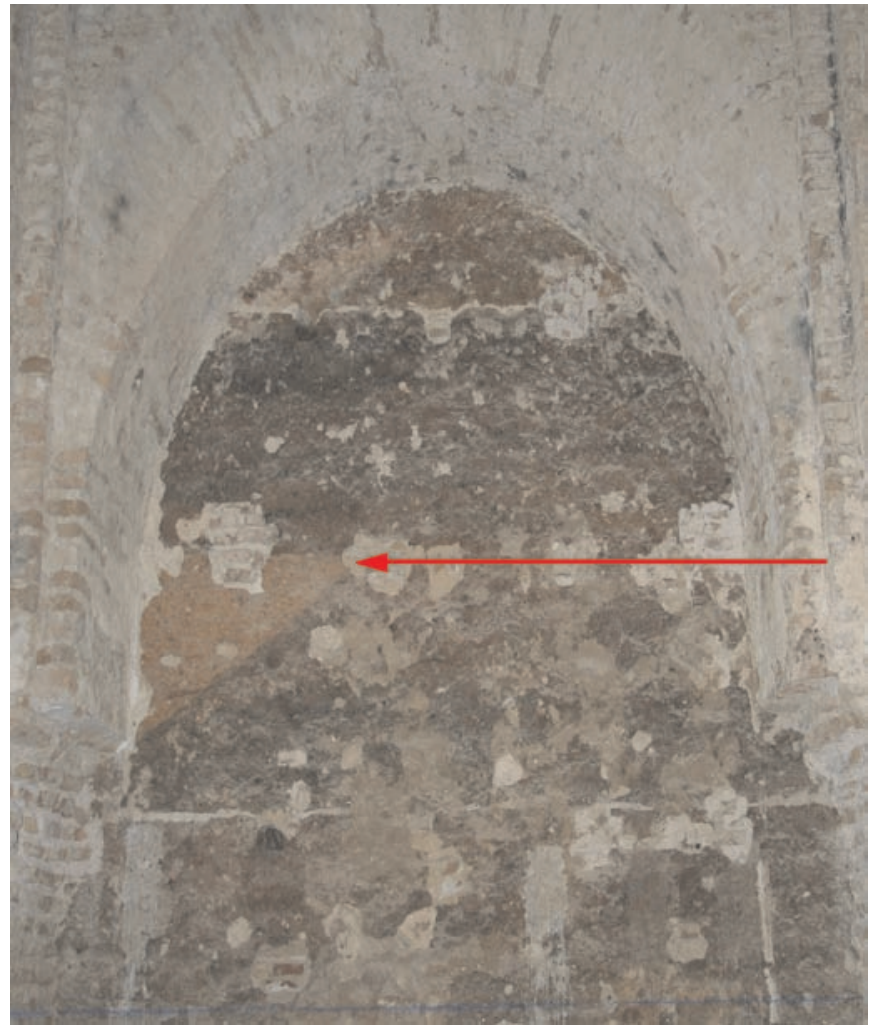

Fig.14. Junta oblicua de los cajones de tapial del cerco de la fase II del proceso III puerta primitiva bajo su protección. Estas torres constituyen en realidad un refuerzo pétreo de los muros de tapial. Hay que destacar que las torres angulares situadas en la zona occidental son las de mayor tamaño (T1 y T6). Esto debe relacionarse funcionalmente con el refuerzo de la primera fase constructiva y con la ubicación al interior de las dos estancias ( 1 y 5$)$ situadas en las esquinas, que desde el principio tienen un tratamiento especial. El alzado original de las torres sería superior al actual, reducción provocada por los embates constantes sufridos por la edificación desde 1369. Así las torres 2, 5, 6 y 7 se conservan actualmente hasta la cota del parapeto.

Proceso III. Fase IV: Ampliación de nave occidental. En esta fase se alarga la nave occidental que aparece en la fase 1, extendiéndola al sur y al norte (hasta el cerco) con la creación de dos estancias, 1 y 5 . Ambas disponen de un acceso al exterior orientado al este y sobre este se sitúa en cada una, un respiradero para proporcionar aire y luz (Fig. 17). Las dos tienen un tratamiento especial. La estancia 1 , realizada en ladrillo, el material más utilizado en el interior del edificio (arcos y bóvedas), cuenta con arcos apuntados moldurados (Fig. 18) y bóveda vaída con

Fig. 15. Vista del castillo desde la torre 6 en la que se aprecian las almenas del primer cerco (Fase I)

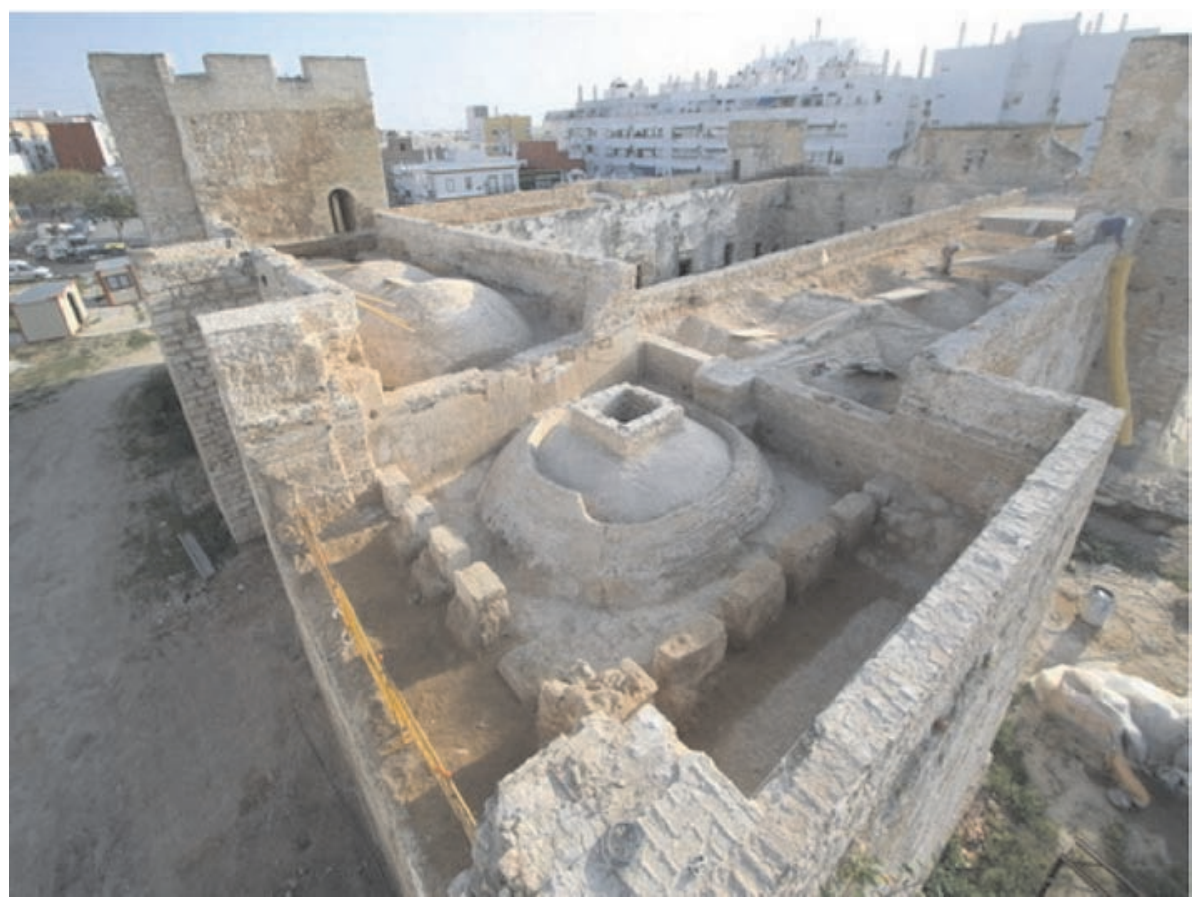

inferior a la que se puede apreciar actualmente). La situación de la torre central de flanqueo en el lienzo sur (T5) es ligeramente asimétrica debido a la ubicación de la
${ }^{16}$ El análisis químico efectuado por Javier Alejandre Sánchez y Juan Jesús Martín del Río como parte del estudio de alzados indica que tanto el mortero como el ladrillo empleado en la construcción de esta estancia son de mejor calidad que el usado en el resto de las estancias que compartimentan el edificio. 


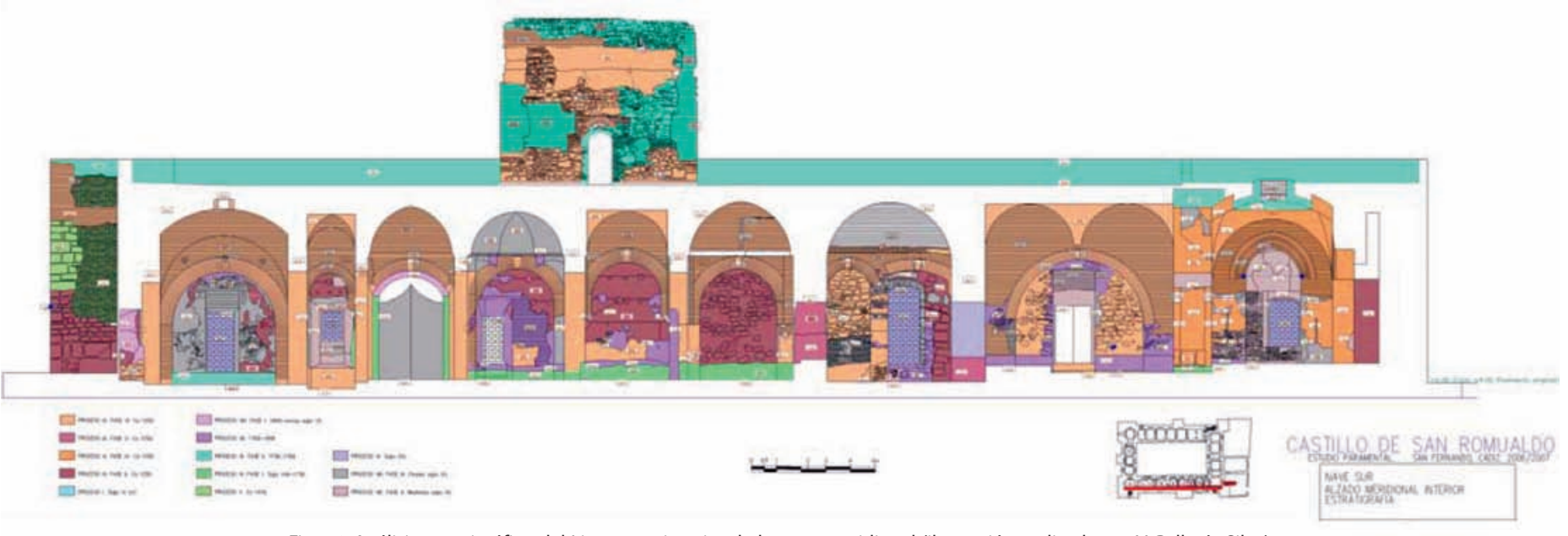

Fig. 16. Análisis estratigráfico del Lienzo sur interior de la nave meridional (ilustración realizada por V. Pallarés Silva)
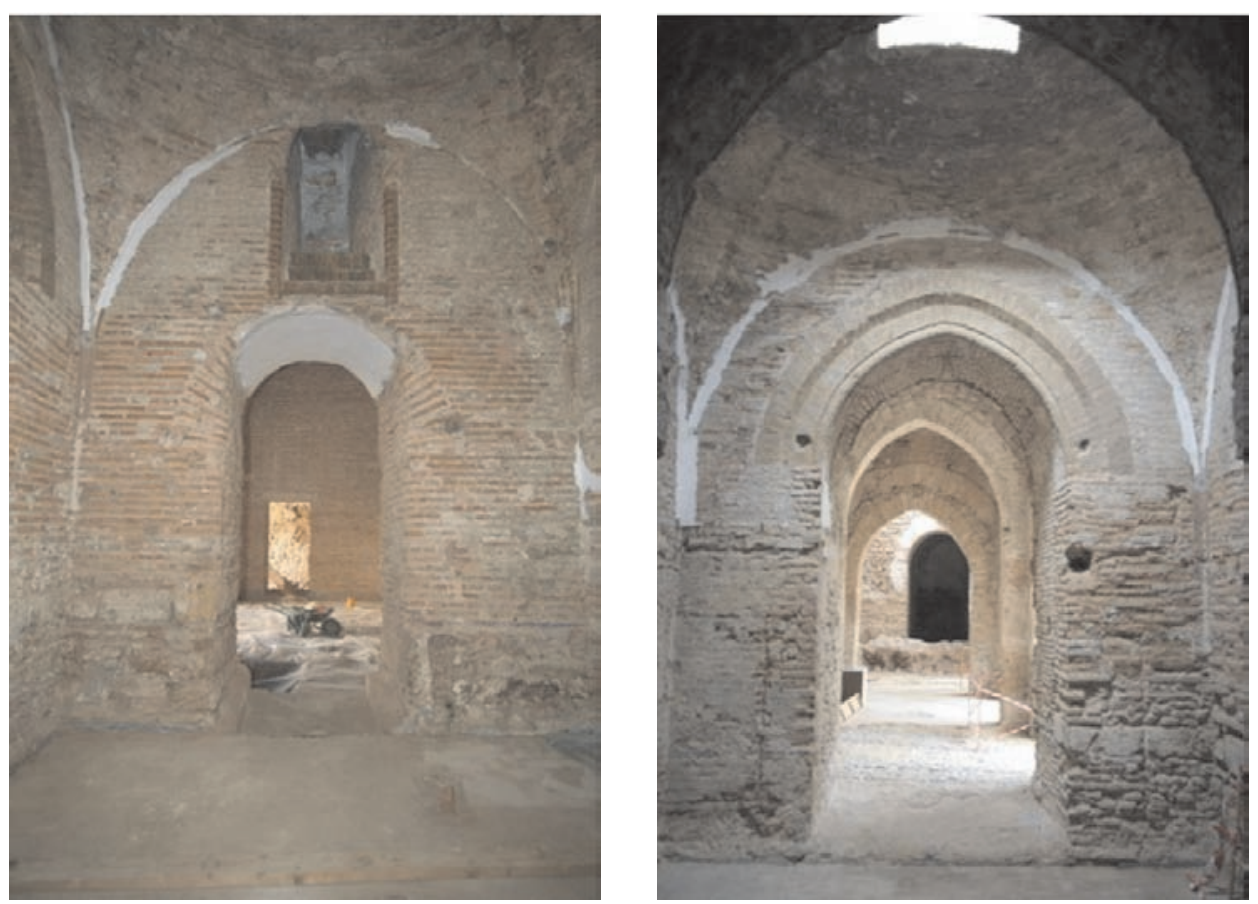

Figs. 17 y 18. Vistas de la estancia 1. En la primera se puede observar el respiradero y en la segunda los arcos apuntados moldurados.

nervaduras ${ }^{16}$. La estancia 5 destaca ya que, a diferencia del resto de estancias, es la única cuyos muros están realizados en piedra; además su puerta conserva los mechinales enfrentados del alamud para reforzarla. Este tratamiento puede estar relacionado con una funcionalidad distinta con respecto al resto del edificio, sobre todo para estos primeros momentos. Posiblemente en la estancia 1 se estableció una primera capilla, que pudo funcionar mientras se iba ejecutando el resto de la obra y que, tras la construcción de las estancias de la nave oriental destinada claramente al culto, quedaría para el uso privado del señor de la fortaleza. De igual forma, los materiales empleados en la estancia 5, el refuerzo de su puerta y el hecho de que se sitúe bajo la denominada torre del homenaje (torre 1) denotan una atención característica de un uso como residencia señorial.

Proceso III. Fase V: Construcción de lienzos interiores principales del edificio, que configurarán la nave meridional, septentrional y oriental. El material constructivo principal sigue siendo el cajón de tapial, al igual que en las fases anteriores, encadenado con ladrillos en puertas, ventanucos y hornacinas. La construcción se inicia en la zona occidental, siendo el lienzo oriental el último en 

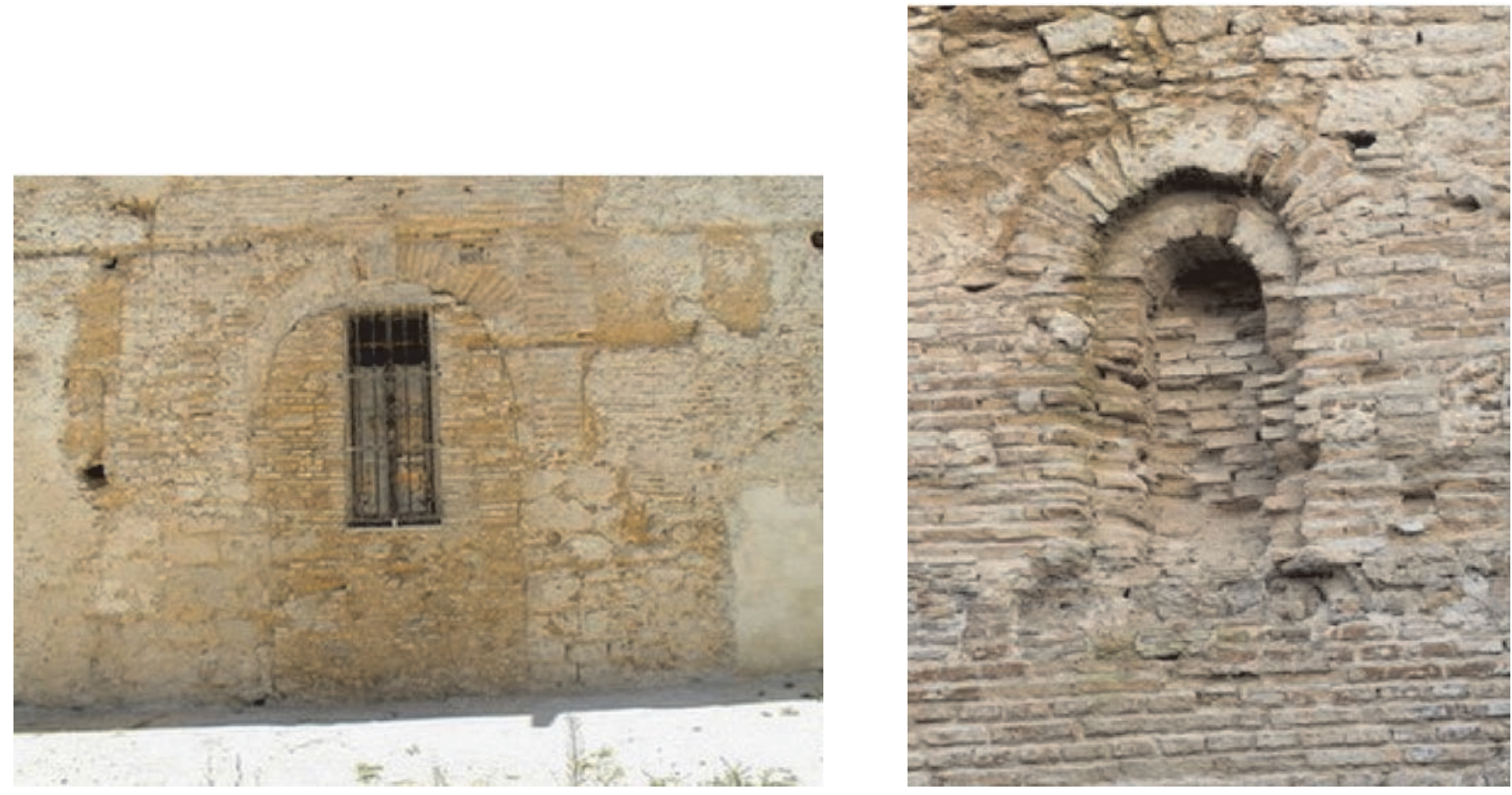

Figs. 19 y 20. Patio de armas. Puerta original de acceso y detalle de la hornacina situada en el lienzo oriental

ejecutarse. En estos momentos se establecen los accesos a cada una de las crujías desde el patio de armas y se hace patente la edificación de una zona de culto en el ala oriental, creándose una hornacina (Fig. 20) destinada a la ubicación de alguna imagen religiosa en el lienzo este del patio de armas. Destaca en el muro sur del patio de armas la puerta principal de acceso desde el exterior. Esta portada es ojival, realizada a base de ladrillo de pie y medio con clave pétrea, y se encuentra enmarcada por alfiz poco pronunciado, cuya base se sitúa muy por debajo de la imposta (Fig. 19). La parte inferior de la puerta estaba conformada por sillarejo irregular. Su factura original queda justificada por su participación en el encadenamiento del tapial del lienzo.

Proceso III. Fase VI: Construcción de las estancias interiores. Es en esta fase cuando se inicia la compartimentación en estancias del castillo, con la construcción en ladrillo de los muros y las diferentes bóvedas de sus interiores. Toda esta obra se adosa a los lienzos de tapial del patio de armas y al cerco exterior, que son reforzados con forros de mampuestos.

La gran variedad y tipología de bóvedas (Fig. 25) que existen en el castillo es una característica que lo define y ha sido resaltada por diversos autores anteriormente. Entre ellas distinguimos:
- Bóvedas esquifadas ochavadas sobre trompas, presentes en la estancia 24 y en la torre noroccidental (en este caso, no se encuentra completa). Encontramos paralelos en la mezquita del Alcázar de Jerez (Jerez de la Frontera), o del Castillo de Torre Estrella (Medina Sidonia), la Torre del Homenaje del Castillo de San Marcos (El Puerto de Santa María, Cádiz), o las de Torre del Carpio, Torre de la Cárcel de Alcalá la Real y Torre de la Cautiva de la Alhambra. En cualquier caso, dicha tipología fue frecuente en edificios cristianos del siglo XIII relacionados con la conquista de Cádiz y posteriores batallas por el control del Estrecho.

- Bóvedas de espejo (Fig. 22) empleadas en las estancias 23,26 y 27 del ala meridional, es decir, en la puerta original y en estancias inmediatas. Este tipo se usa frecuentemente en puertas bajomedievales como las de Jerez en Tarifa o la de Puerta de Armas de la Alhambra, aunque el número de las fechadas a lo largo del siglo XIII (sin especificarse momento) es mayor (Puerta de la Justicia de la Alambra, puerta del Sol de Toledo, Castillos de Álora, Alcalá la Real, Cazorla, Segura de la Sierra, Antequera, etc.).

- Bóvedas vaídas (Fig. 21) se dan en el ala oriental y occidental del edificio. Es una bóveda muy utilizada en España desde el siglo XI; de hecho se trata del tipo bizantino radial más simple y frecuente desde el siglo VI, perdurando hasta el siglo XVIII en iglesias y ermitas. En el 

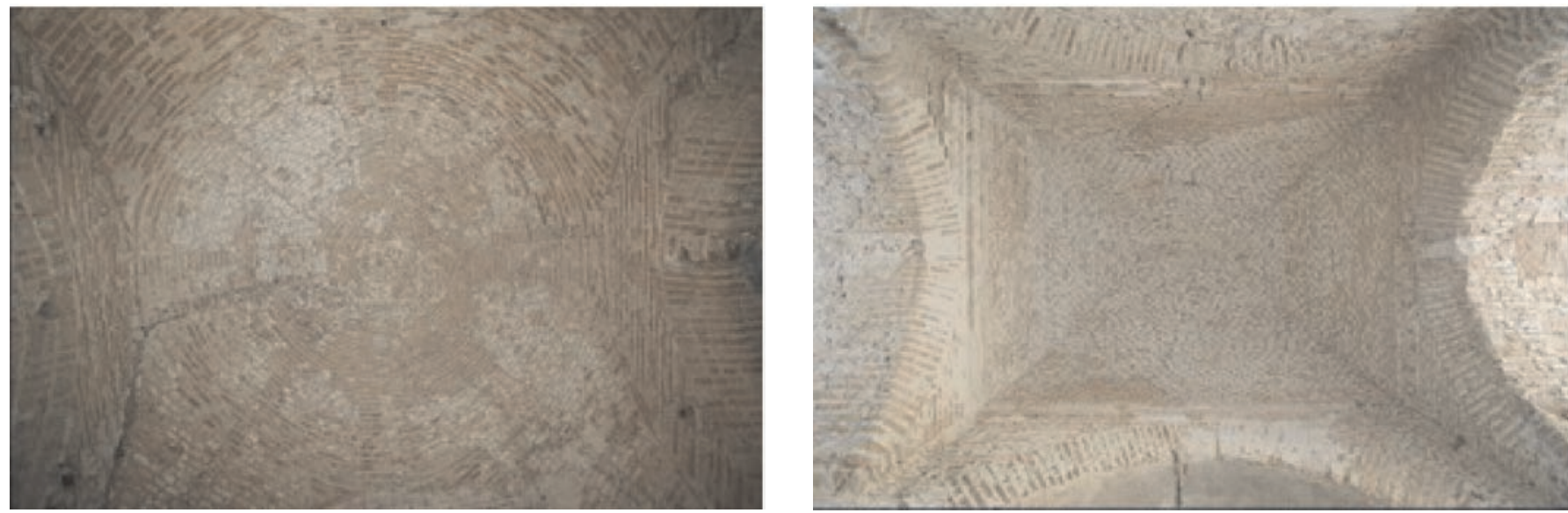

Figs. 21 y 22. Diversidad de bóvedas. Bóveda vaída con nervaduras en estancia 16 y bóveda de espejo

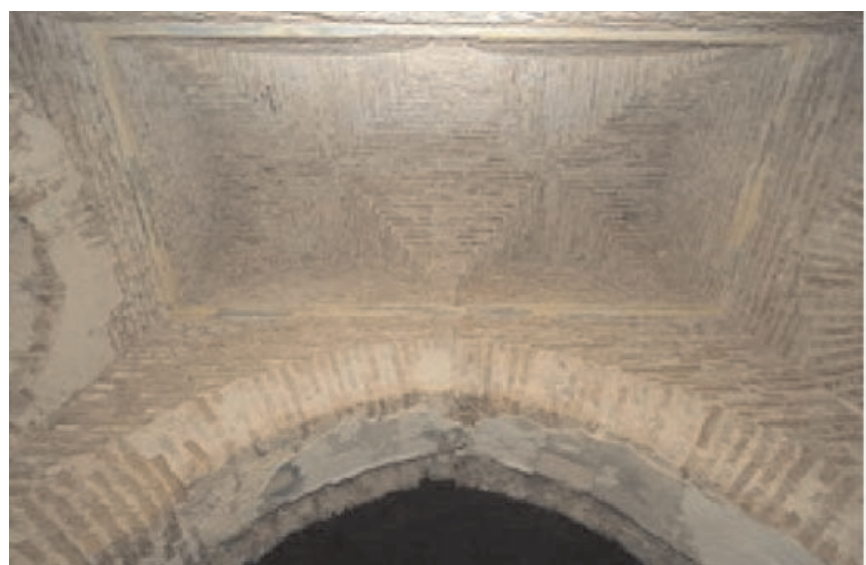

Figs. 23 y 24. Diversidad de bóvedas. Bóveda de aristas y bóveda de cañón

entorno inmediato los paralelos reconocibles en la arquitectura islámica son múltiples desde las Calahorras de Córdoba o Gibraltar hasta la alcazaba de Málaga murallas de Sevilla, castillos de Niebla, Bujalance, Alcalá de Guadaíra, Alora, Salobreña, etc.

-Bóvedas de cañón (Figs. 24 y 26) utilizadas sobre todo en las estancias del ala septentrional y en los tramos cortos entre estancias. Es un tipo atemporal muy adecuado como refuerzo de los muros a la par que efectivo en la lucha contra los incendios. Debe resaltarse su uso en el vecino castillo alfonsí de Torre Estrella (Medina Sidonia).

- Bóveda de aristas (Fig. 23): utilizadas en las estancias 22,25 y 29 en el ala sur y en la estancia 4 del ala occidental. Es tal vez el tipo más antiguo del castillo y, como las otras, está presente tanto en el período islámico como en el cristiano mudéjar. Hemos de resaltar que en Villalba del Alcor se utilizan en la antigua iglesia del siglo XIII.

Las bóvedas empleadas en San Romualdo se entien-

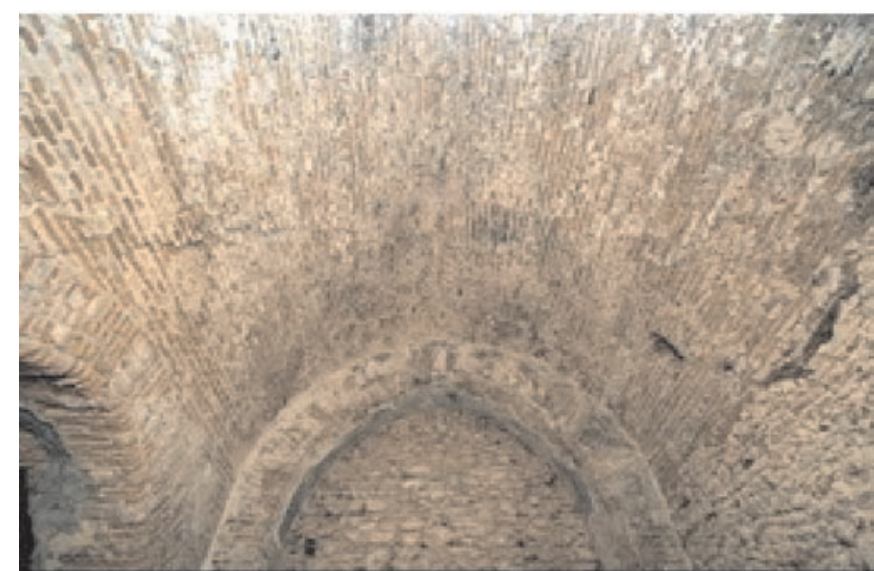

den dentro de una tradición islámica con amplio desarrollo durante el siglo XIV, si bien es cierto que los paralelos más seguros (Torre Estrella, San Marcos, Jerez) se fechan en las décadas centrales del siglo XIII. Es habitual el uso de una clave pétrea señalada, presente en la portada de ingreso, y en la mayor parte de los arcos de las estancias. Es esta una solución local de probable origen islámico y desarrollo en el primer mudéjar. Hay que destacar que la mayor parte de los arcos del edificio estaban avitolados (Fig. 29).

En estos momentos se observa una diferenciación en la construcción de las estancias del ala oriental, con arcos moldurados (estancias 15, 16 y 17), hornacinas (estancia 17), linternas (estancia 21) y la decoración de nervios entrelazados en forma de cruz en la bóveda de la estancia 16 (Fig. 21). Esta diferenciación interior se hace patente en el exterior desde el proceso anterior, cuando se crea en el patio una hornacina en esta zona. La singularidad de estas estancias se pone en relación con la instalación preconcebida en la fortificación de un ámbito destinado al culto 


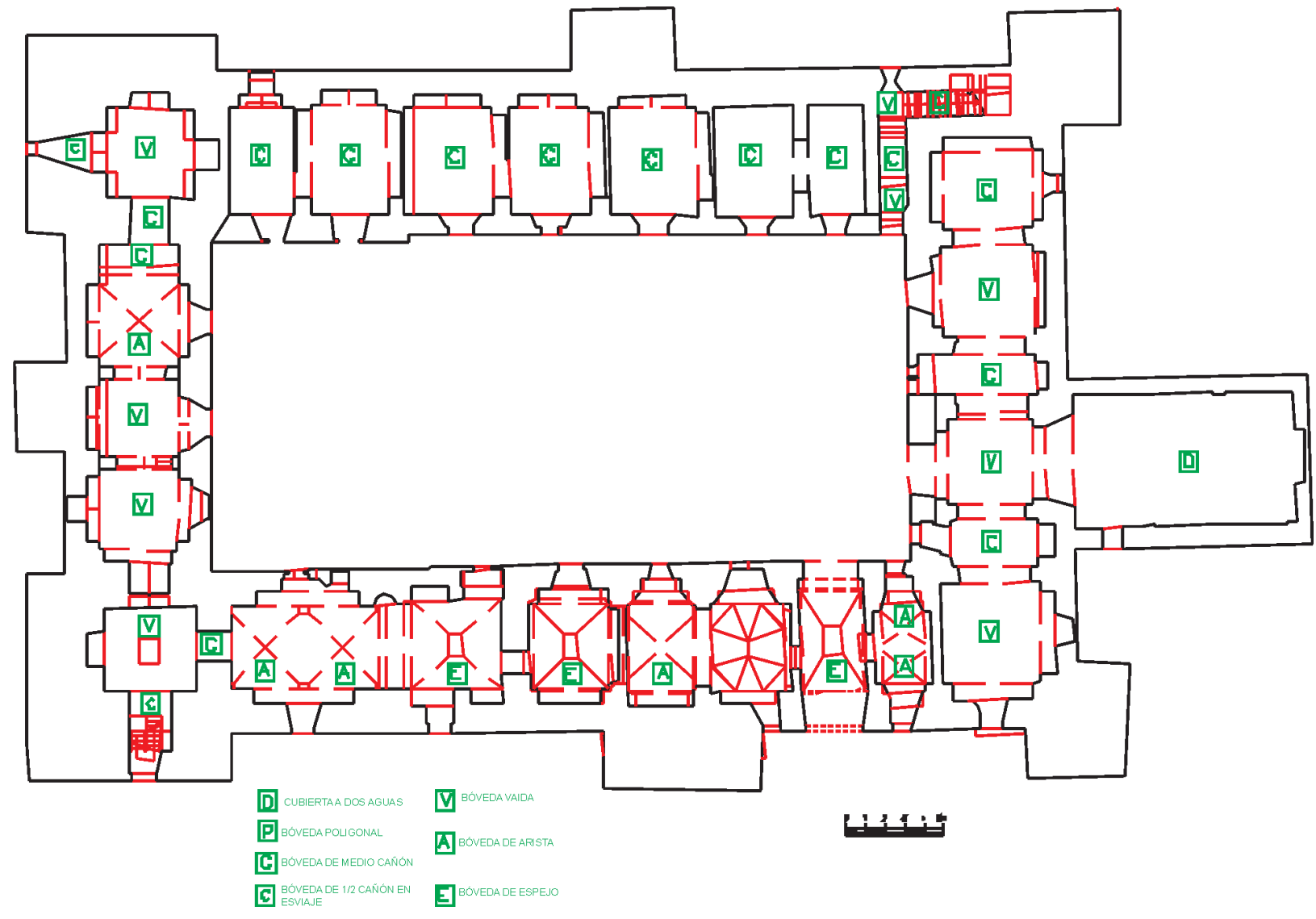

Fig. 25. Tipología de bóvedas en planta baja

cristiano, posiblemente la capilla de Santa María que en 1338 citan las fuentes ${ }^{17}$ se estableciera en este ala, más amplia y adecuada, destinándose la estancia 1 a capilla privada.

El trasdós de las bóvedas se rellena con el mismo material empleado en la construcción de los muros (tierra $\mathrm{y}$ cal muy compactadas $)^{18} \mathrm{y}$ sobre éste se recrecen las torres con cajones de tapial encadenados principalmente con ladrillo. El antiguo adarve se ciega con ladrillos o tapial y se recrece con nuevos cajones de tapiales conformando el aspecto definitivo del edificio que se eleva unos dos metros sobre el nivel del adarve de la fase II. La antigua escalera se sustituye por otra, lo mismo ocurriría con la merlatura cuya morfología en estos momentos desconocemos, puesto que no se ha conservado. En el año 2003 se documentó una cruz patada (Fig. 27) en relieve, cubierta con almagra,

\footnotetext{
17 Documento recogido por Joaquín Cristelly (Cristelly, 1891, p. 69). La advocación a Santa María es propiamente alfonsí. Ejemplos cercanos de la construcción de lugares destinados al culto durante su reinado los tenemos en el castillo de San Marcos de El Puerto de Santa María o en el alcázar de Jerez de la Frontera.

${ }^{18}$ La cerámica que encontramos en el relleno de estas bóvedas apunta una cronología de segunda mitad del siglo XIII y primera mitad del XIV.
}

sobre la puerta original ${ }^{19}$ en la fachada meridional, que se identificó con la orden de Santa María de España, absorbida por la de Santiago y que ubicamos en este proceso. De igual forma, se han localizado otras dos cruces al interior, una en cada una de las caras de la clave del arco situado entre las estancias 11 y 12 .

Proceso IV: destrucción y abandono bajomedieval. En 1370 se produjo el ataque de la escuadra lusa (enmarcado en las luchas entre Enrique de Trastámara y Pedro I) que arrasó la isla de Cádiz y que afectó al castillo destruyendo sus almenas, como lo indica un privilegio de 1411 en el que el rey Juan II donó el lugar de la Puente a los Suazo (Mosig, 2005, p. 68). Tras este ataque, el estado de ruina y abandono del edificio se mantuvo hasta que pasó a manos de la familia Suazo. Situamos en estos momentos la destrucción del almenado original (cómo dice el texto), del frente oriental de la torre 4 y posiblemente del alzado de algunas torres, aunque en este caso, no podemos descartar que se produjera en los

${ }^{19}$ Esta puerta estaba protegida por un buzón matafuegos localizado durante la intervención en la cubierta. 


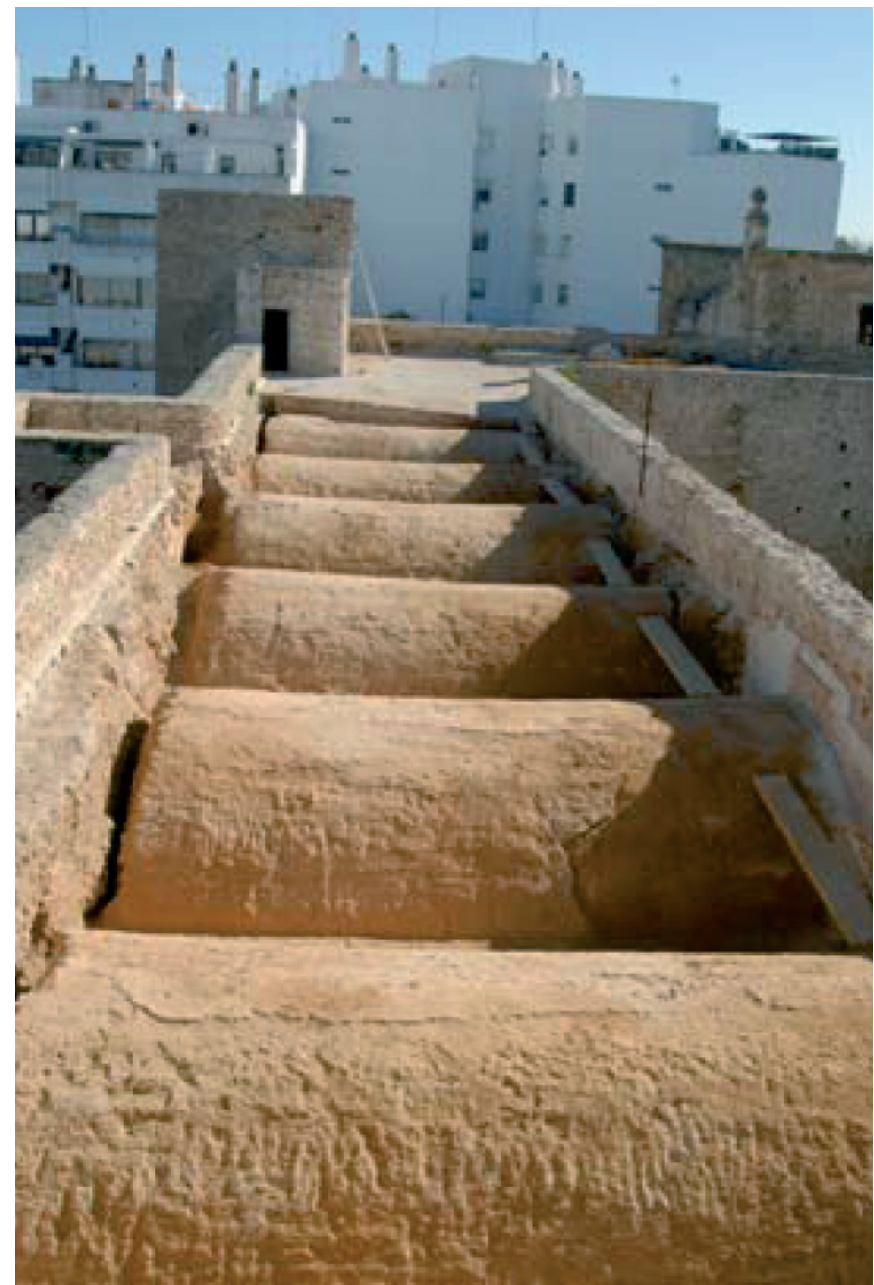

Fig. 26. Detalle del trasdós de las bóvedas de cañón en la nave septentrional tras el proceso de vaciado

ataques de finales del siglo XVI y primer cuarto del siglo XVII, ya que la documentación arqueológica del trasdós de las bóvedas y la relación estratigráfica en los alzados no aclaran nada al respecto.

Proceso V: Reconstrucción bajomedieval. En 1408, los regentes del rey Juan II (Fernando de Antequera y Catalina de Lancaster) donan a Juan Sánchez de Suazo el señorío de La Puente, que perduró en manos de la familia Suazo hasta 1492, fecha en la que pasa a la familia Ponce de León. En un informe que hace Sánchez de Suazo al rey sobre el estado del inmueble en 1411, indica su Intención (es) de hacer reparar la dicha casa y heredades, siendo probable que la actuación de Juan Sánchez de Suazo consistiera en potenciar la doble función del edificio como casa solariega y como casa fuerte. En este proceso se sitúa la reconstrucción de diversas zonas del edificio, en concreto el frente oriental de la torre 4, en la que se aprecia una distribución irregular de los sillarejos en las esquinas y un emparchado general de la torre o el interior de la nave occidental, donde los arcos antiguos son reforzados por arcos apuntados más pequeños. La estancia 5, situada en la esquina noroccidental bajo la denominada Torre del Homenaje y que parece relacionada con una dependencia señorial, estuvo decorada con pinturas gótico-mudéjares (Fig. 28) de motivos vegetales y geométricos que situamos a partir de estos momentos. Con respecto al foso, se colmató en los siglos XIV y XV (Sáez et al., 2004, p. 109).

Proceso VI: Sede de la Iglesia parroquial. En el asalto de la escuadra angloholandesa en 1596, la ermita de San Pedro, a extramuros del castillo y con funciones parroquiales, es destruida. Al menos desde mediados del siglo XVII, la parroquia isleña se situó dentro del castillo, en la zona donde se encontraba la antigua capilla medieval de Santa
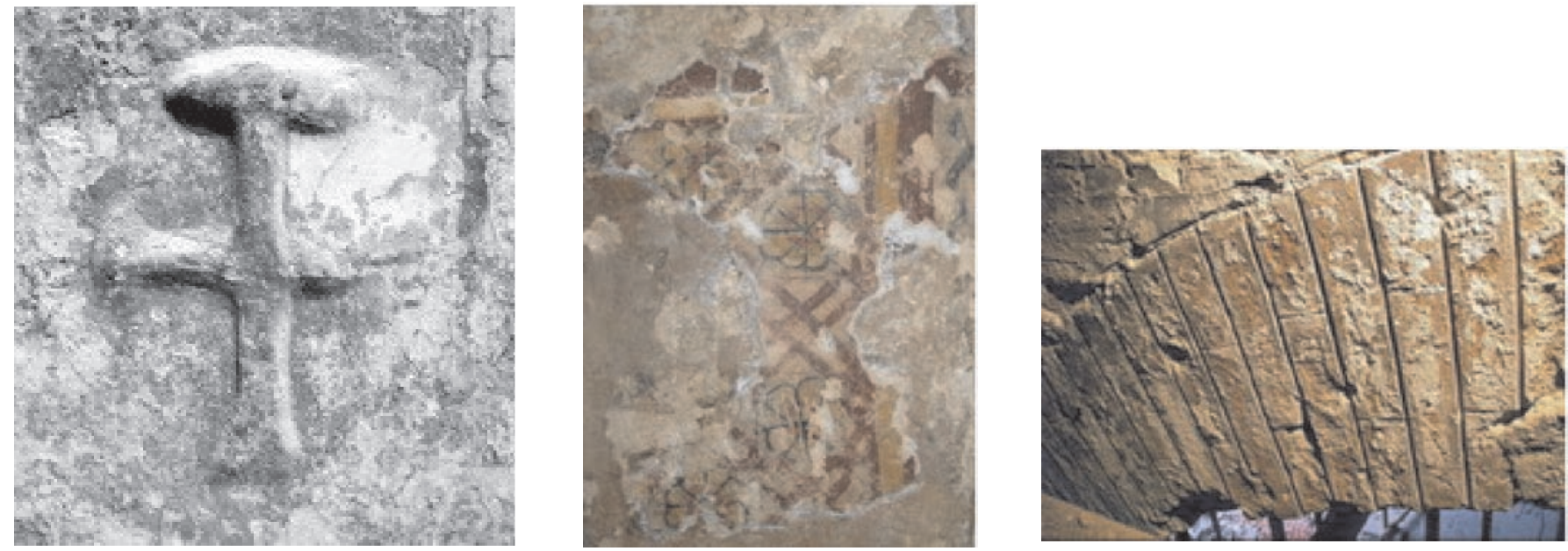

Figs. 27, 28 y 29. Cruz patada sobre la primitiva puerta, pinturas gótico-mudéjares en estancia 5 y avitolados característicos de la mayoría de los arcos del castillo 


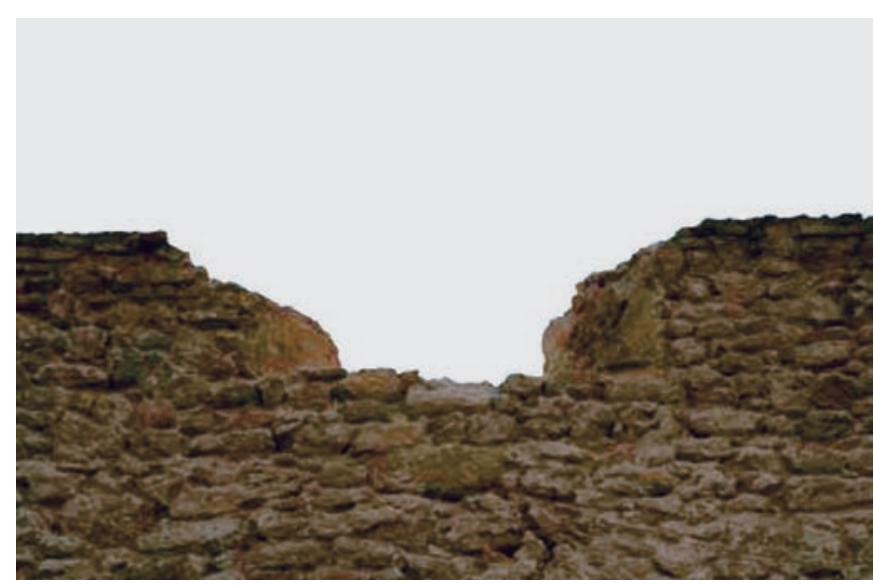

Fig. 30. Detalle de almenado para artillería

María (la nave oriental). Esta adaptación de la fortaleza (que seguía perteneciendo a los duques de Arcos y conservando sus funciones defensivas, ya que en ella había una guarnición) a parroquia conllevó una serie de obras de reformas divididas en dos momentos, que tienen como punto de inflexión la creación del edificio rectangular oriental que identificamos con la capilla de la Hermandad del Rosario (Fig. 32), a partir del año 1736 (Mosig, 2005, p. 123).

Proceso VI. Fase I. Siglo XVII hasta 1736. Las reformas en los lienzos durante estos momentos parecen corresponder a dos tipos de actuaciones relacionadas con su doble funcionalidad, por un lado el refuerzo militar del edificio y por otro su adaptación a parroquia. En el asalto de 1596, o quizás en el ataque inglés de 1625, el lienzo septentrional del patio de armas debió quedar muy dañado (pierde parte de su frente, sobre todo en la zona oriental), por lo que posteriormente se reconstruye y se refuerza con una serie de muros perpendiculares a éste, a modo de estribos ${ }^{20}$, que ampliaban la nave norte posiblemente para establecer capillas o altares. Toda la nave oriental se convirtió en un enorme osario, destacando la gran cantidad de restos óseos aparecidos en relación al poco tamaño de los sondeos. Así el estudio paleopatológico y antropológico se ha realizado sobre 14.524 huesos identificables y 716 piezas dentarias ${ }^{21}$. $\mathrm{El}$ ala sur se compartimenta en varias estancias con muros divisorios y se abren nuevas puertas al patio de armas. En

\footnotetext{
${ }^{20}$ Muros documentados durante la intervención de subsuelo.

${ }^{21}$ Estudio incluido en el trabajo de intervención arqueológica y realizado por la paleopatóloga Milagros Macías López, en el que se destaca la escasez de restos óseos de mayor tamaño, como articulaciones o huesos largos, producto de la remoción del terreno, una vez desacralizado el lugar, para su traslado a camposanto.
}

los lienzos exteriores, se crean aspilleras para artillería, que se pueden apreciar en el frente sur (torre 4) y en oriental (Fig. 30). También la torre 1 presenta este almenado, aunque el que vemos ahora es producto de una rehabilitación de finales del siglo XX. Sí se conserva parte del preparado del original. Se abre el acceso actual al castillo con una gran portada adintelada, que será transformada en el siglo XX, sobre la que se encuentra una hornacina que guardaría alguna imagen religiosa (Fig. 31). Este podría ser el que en 1717 se ordenó realizar para que el cura o los vecinos que acudían a la parroquia tuvieran un paso independiente de los guardias del castillo (Mosig, 2005, p. 126). Sea o no, este paso era más apropiado para carruajes modernos y artillería que el abierto en este lienzo durante el proceso III.

Proceso VI. Fase II. La obra fundamental de esta fase sería la construcción de la capilla del Rosario en fechas posteriores a 1736, adosándose al muro exterior de la fachada oriental del castillo. La creación de este edificio supone el derribo de la torre central situada en este lienzo que ya debía de encontrarse en malas condiciones tras los ataques de 1596 y 1625. Bajo el edificio se creó una gran cripta que anuló toda la estratigrafía original en esa zona. En estas fechas también se reconstruye el parapeto exterior del edificio. Entre 1737 y 1742 (Mosig, 2005, p. 126) se añadió una espadaña a la torre central del lienzo sur (T5), de la que bajo su cornisa, aún se conserva parte de su decoración de motivos vegetales. Puede que como parte de esta labor de acondicionamiento de la torre se encontrara la realización de los tres relojes de sol que aparecen en cada uno de sus lienzos exteriores. La falta de relación de la estratigrafía vertical no nos aclara más que son posteriores al siglo XIII y anteriores al Proceso VII.

En la zona norte de la estancia 5, se superpone sobre la decoración gótico-mudéjar una pintura de época barroca con motivos religiosos, entre ellos cruces patriarcales y un corazón de Jesús con los anagramas de Jesucristo (JHS, Jesus Hominum Salvator) y el Ave María (letras A y M entrelazadas) en su interior, que podría identificarse con el altar de una de las cofradías que se instalaron en el castillo durante los siglos XVII y XVIII: la Congregación del sagrado Corazón de Jesús ${ }^{22}$.

Tras la construcción de la nueva Iglesia Mayor Parroquial en San Fernando, consagrada en 1764, la parroquia del castillo fue abandonada y el terreno secularizado (Mosig, 2005, p. 127).

22 Esta cofradía se fundó en 1753 (Mosig, 2005, p. 37). 

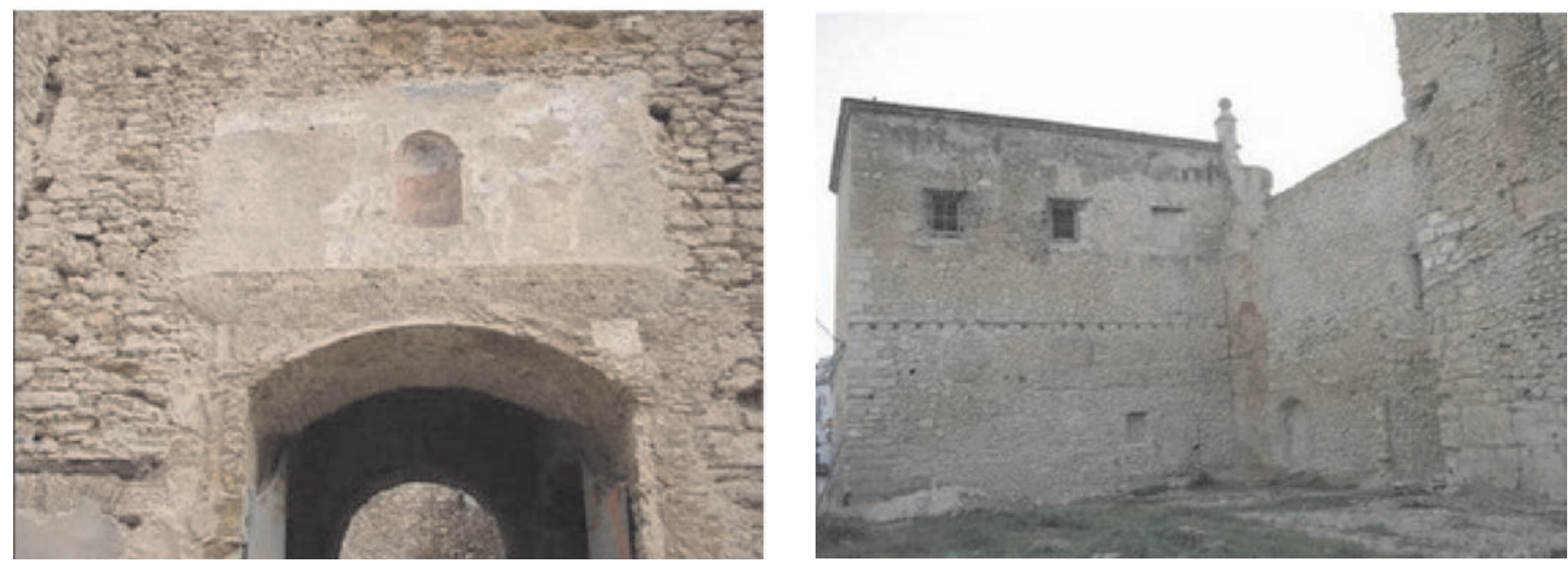

Figs. 31 y 32. Detalle de la puerta barroca y del edificio anexo identificado con la capilla del Rosario

Proceso VII: este proceso enmarca la adaptación del edificio a cuartel de batallones y brigadas de la armada, documentada desde $1769^{23}$ a 1808 , aunque hasta 1846 sigue en manos militares. De estos momentos es la apertura de la mayor parte de puertas y ventanas, que podemos observar actualmente y que responden a una nueva distribución del interior del edificio. Destacan los vanos con arcos adintelados pétreos del patio de armas, que se cubrieron con los llamativos guardapolvos conopiales de remates diversos en borla (para señalar los grados militares), realizados con fábrica de ladrillo a soga y enlucidos a la almagra (Fig. 33).

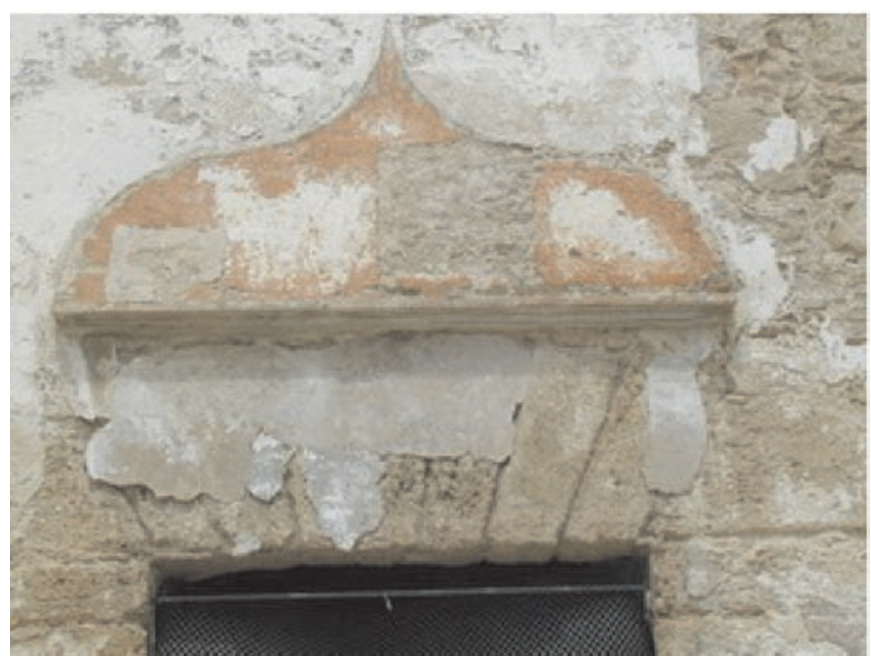

Fig. 33. Guardapolvo conopial en una de las puertas del patio de armas

${ }^{23}$ En concreto, julio de 1769, según un documento localizado en el Archivo Municipal de San Fernando.
Proceso VIII: usos domésticos. Una vez que el castillo pierde su uso militar a mediados del siglo XIX, entrará en una fase de deterioro que se prolongará durante todo el siglo XX, hasta el momento de su expropiación. Así en el año 1924, la propiedad del castillo pasa a manos de don Fidel Pérez de Diego que lo compró en subasta pública tras la enajenación de los bienes de la casa de Osuna por sus acreedores. Desde entonces su destino se vio unido al de esta familia. En sus exteriores se irán adosando edificaciones que le harán perder su fisonomía inicial y en el interior sus estancias se destinarán a diferentes usos (viviendas, restaurante, almacén de material de construcción, taller de cristalería y carpintería de aluminio, etc.) que se reflejan en obras de menor envergadura, como tabiquerías y apertura de nuevas ventanas y puertas, que le dan el aspecto que hasta hoy conocíamos. Este proceso se ha dividido en varias fases, finales del siglo XIX e inicios del siglo XX (fase 1), mediados de siglo (fase 2) y final del siglo XX (fase 3).

Proceso IX: comprende todas las actuaciones realizadas tras la expropiación del edificio, como eliminación de tabiques contemporáneos y de los adosados al exterior, cegamientos de ventanas y puertas para impedir el acceso, etc.

\section{CONCLUSIONES}

El análisis arqueológico ha permitido conocer la secuencia constructiva completa de la edificación. Sobre la problemática de su origen, podemos concluir:

1. No hay evidencias directas de la existencia una edificación previa al castillo en ninguno de los alzados estudiados hasta el momento. Por el contrario, la unidad 

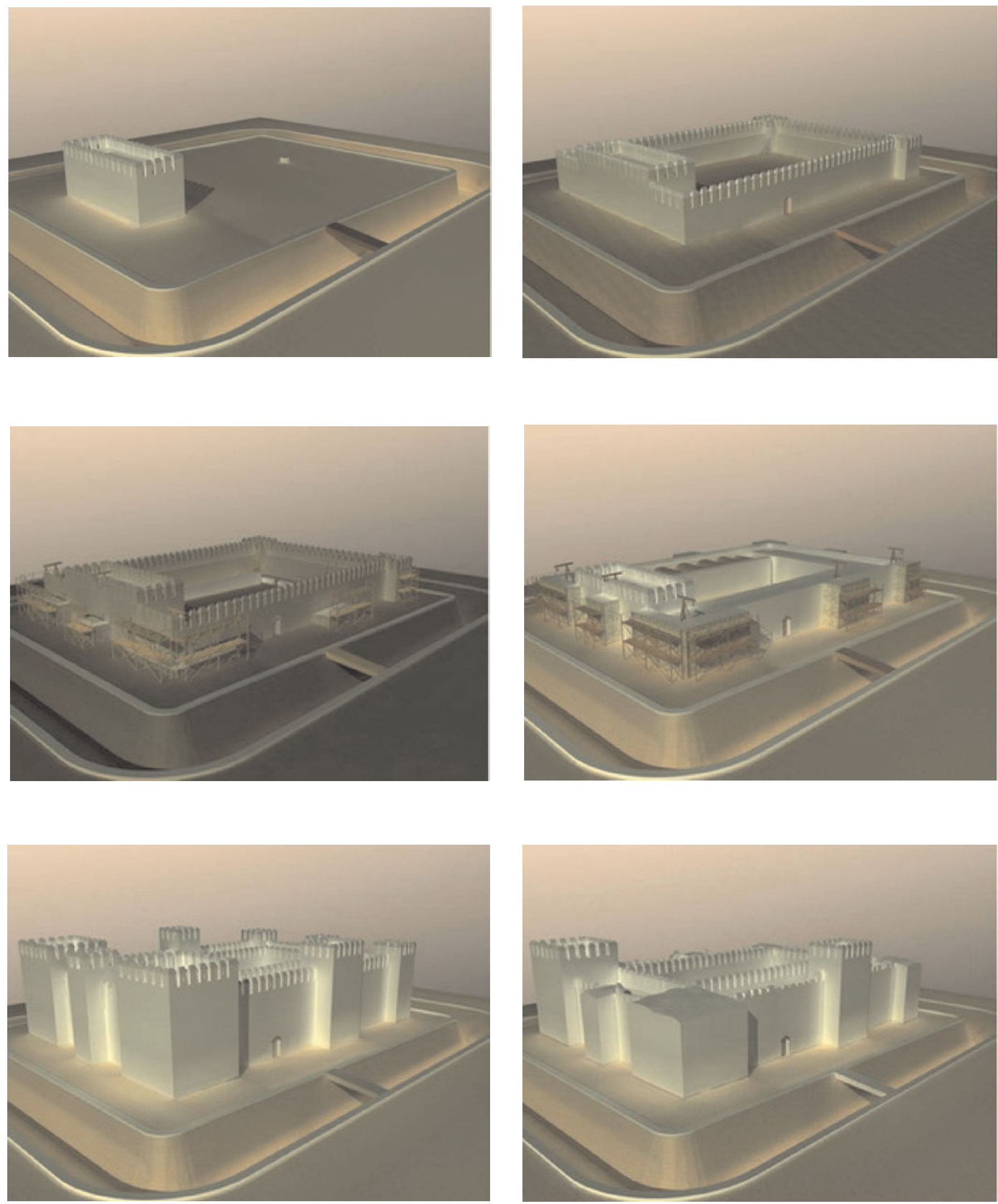

Figs. 34-39. Reconstrucción tridimensional de la evolución constructiva del castillo realizada por V. Pallarés Silva. Fig. 34. Proceso III fase 1: construcción de la nave occidental y delimitación de la edificación con la construcción del foso. Fig. 35. Proceso III fase II: Erección del cerco exterior almenado. Fig. 36. Proceso III. Fase III: Construcción de las torres. Fig. 37. Proceso III. Fase VI: Construcción de las naves interiores y recrecido de torres y alzados. Fig. 38. Proceso III. Fase VI. Reconstrucción del castillo tras finalizar el proceso III. Fig. 39. Destrucción en 1370 
compositiva, claridad arquitectónica y homogeneidad de la fábrica sugieren una construcción ex novo fundamentada en un replanteo unitario sobre un terreno preacondicionado y explanado. Sin embargo, los sillares empleados en las torres nos hablan de una reutilización de piezas acarreadas de una construcción anterior situada en las inmediaciones ${ }^{24}$.

2. Tampoco hay evidencias de una fortaleza anterior al siglo XIII, ya que el atizonado de los sillares de la torre 4 no es suficiente recurso para hablar de una fortaleza califal. De igual forma, las dos primeras fases del proceso III se podrían interpretar como una edificación anterior al castillo que conocemos en la fase VI de este proceso. Sin embargo, en la intervención de subsuelo no han aparecido materiales que lo confirmen ${ }^{25}$ y en cuanto al estudio de alzados la continuidad en la técnica y los materiales nos hacen pensar que forman parte del proceso constructivo general, como un primer esfuerzo edilicio que debía proteger la obra que se iba a realizar. No obstante, no descartamos esta hipótesis que puede aclararse en futuras actuaciones que se centren en la cimentación del edificio.

3. Con respecto a la hipótesis del ribat, se han esgrimido, entre otros, argumentos como la comparación de su planta con la del ribat de Susa o la compartimentación de su interior en pequeñas estancias abovedadas concebidas como celdas, cada una de las cuales disponía de una puerta al gran patio rectangular. Frente a esto hay que señalar que el quadribugium latino puede ser un referente para cualquier edificación militar del siglo XIII con independencia de su filiación. Los paralelos con los ribats de Susa y Monastir en Túnez son tan válidos como los de los monasterios de Tentudía, Guadalupe, la extraña iglesia fortificada de Villalba del Alcor o el convento de Santa Clara de Moguer. De igual forma, el estudio de alzados ha puesto de manifiesto que la mayor parte de las puertas hoy visibles no son originales, así la mayoría corresponden a vanos abiertos durante la transformación en cuartel, en su mayoría ventanas, convertidas en puertas a lo largo del siglo XX. La compartimentación en celdas no se corresponde con la distribución inicial, al contrario, las naves se muestran como grandes salas diáfanas y las tabiquerías que existían se hicieron en obras posteriores, sobre todo contemporáneas.

\footnotetext{
${ }^{24}$ Como ya hemos mencionado, los autores de las intervenciones arqueológicas en el foso del castillo no descartan la vinculación del foso con una edificación previa.

${ }^{25}$ Conocemos la existencia, referida anteriormente, de estructuras y en su caso, de materiales islámicos asociados a estas, documentados en intervenciones arqueológicas previas, aunque hasta ahora no se ha podido constatar su relación directa con ninguno de los procesos constructivos de edificación del castillo.
}

4. En cuanto a que la fortaleza concluída en el proceso III, fase VI, fuera musulmana, la problemática del castillo ha radicado en la existencia de recursos constructivos que podrían considerarse tardoislámicos o mudéjares, ya que el siglo XIII se encuentra de frontera entre los dos mundos. Esto ocurre con la gran variedad de bóvedas del edificio. Sin embargo, el análisis nos revela que toda la obra (lienzos, bóvedas y torres) corresponde a un mismo proceso constructivo y que desde los primeros momentos se establece un ámbito de culto cristiano que queda patente en los recursos utilizados en nave oriental (arcos con ladrillos moldurados, bóveda con nervadura cruciforme, hornacinas interiores y exteriores, etc.), en la estancia 1 y en otras partes del edificio (cruces). Dicho proceso fue necesariamente rápido, observándose elementos comunes en cuanto a la técnica y los materiales, en las distintas fases que nos permiten hablar de un gran proceso constructivo en el que se primó inicialmente la edificación y protección de su interior, con el cercado de un recinto defensivo antes de pasar a culminar las distintas dependencias.

El resultado final concuerda más con el de un convento fortificado que con el de un ribat islámico. Posiblemente, este carácter militar-monacal estuviera relacionado con una orden militar, quizás la Orden de Santa María de España, cuya presencia en la zona es manifiesta tras las campañas de Alfonso X. Castillos como el de San Marcos del Puerto de Santa María o el alcázar de Jerez nos ofrecen paralelos de lo que sería un programa de obras cristiano materializado por alarifes musulmanes que emplearían un amplio elenco edilicio de bóvedas, aparejos y elementos musulmanes. Otros edificios como el castillo de Torre Estrella en Medina Sidonia, levantado por la citada orden, parecen una réplica del de San Romualdo, pero con la salvedad de su ubicación en altura sobre un risco.

En definitiva, arcos, roscas y materiales implicados parecen responder a esquemas locales utilizados en la edilicia almohade jerezana conviviendo con tipos góticos de tradición castellana.

\section{Bibliografía}

Abreu, Fr. P. de (ed. 1866): «Causas de las enemistades de algunos reinos y provincias de España» en Historia del Saqueo de Cádiz por los ingleses en 1596. Cádiz, pp. 31-165.

Castro Rossi, A. de (1858): Historia de Cádiz y su provincia desde los tiempos más remotos hasta 1814. Reedición en Facsímil de Imprenta de la Revista Médica, 1985, Diputación Provincial de Cádiz.

Cristell y Laborde, J. (1891): Ligeros apuntes históricos y colección de citas, documentos y datos estadísticos de la ciudad de San Fernando desde los tiempos más remotos hasta 1823. San Fernando.

Diario de Cádiz (22 de agosto de 1984): «Ramón Corzo habló de la relación entre Tartessos y Cádiz». 
Eslava Galán, J. (1985): «El fuerte cuadrado en España». Revista de Arqueología $n^{\circ} 55$, p. 50.

Fierro Cubiella, J. A. (1991): El Castillo del «Lugar de la Puente» en San Fernando. Cádiz.

González Jiménez, M. (1983): «La obra repobladora de Alfonso X en las tierras de Cádiz», en Cádiz en el siglo XIII. Actas de las Jornadas Conmemorativas del VII Centenario de la muerte de Alfonso X el Sabio (1983. Cádiz). Cádiz, pp.7-20.

Horozco, A. de (ed. 2001): Historia de Cádiz (Edición, Introducción y Notas de Arturo Morgado García). Cádiz.

Mosig Pérez, F. (2005): Aproximación a la historia del Castillo de San Romualdo. Patrimonio de la Ciudad de San Fernando. Editorial El Penitente. San Fernando.

Mosig Pérez, F. (2005): Historia de las Hermandades y Cofradias Isleñas. Imprenta «La Isla». San Fernando.

Romero de Torres, E. (1934): Catálogo Monumental de España. Provincia de Cádiz. Ministerio de Instrucción Pública y Bellas Artes. Madrid.

Sáez Espligares, A.; Torres Lázaro, J. y Sáez Romeero, A. M. (2009): «Monedas bajomedievales del Castillo de La Puente (San Fernando, Cádiz). Aportaciones a los orígenes y evolución de la fortaleza». Actas de XIII Congreso Nacional de Numismática (Cádiz 22, 23 y 24 octubre de 2007). Cádiz (en prensa).

Sáez Espligares, A. y Sáez Romero, A. M. (2005): «Reflexiones acerca del
Concejo de la Puente: origen y desarrollo en los ss. XIII-XIV", Revista de Arqueología y Territorio Medieval, no 12.2, pp. 7-33.

Sáez Montero, A. M.; Montero, R.; Montero, A.I.; Sáez, A., y Díaz, J. J. (2004): «Anotaciones al recorrido de las vías Augusta y Heraclea a su paso por San Fernando (Cádiz). Novedades arqueológicas y paleogeográficas», Antiqvitas, 16, pp. 105-119.

Tabales Rodríguez, M. A. (2003): Aproximación arqueológica al Castillo de San Romualdo, San Fernando, Cádiz, informe del estudio paramental iniciado en el año 2003 (Depositado en la Delegación Provincial de Cultura de la Junta de Andalucía en Cádiz).

Tabales Rodríguez, M. A. (2002): Sistema de análisis arqueológico de edificios históricos, Universidad de Sevilla.

Torremocha Silva, A.; Sáez Espligares, A. y López Garrido, J. L. (2000): Informe preliminar de la actuación arqueológica de urgencia realizada junto al Castillo de San Romualdo en el solar localizado en Cl Augusto Miranda ela Plaza Font de Mora (San Fernando, Cádiz). Julio de 2000. San Fernando.

Torres Balbás, L (1950): «El Castillo del Lugar de la Puente, en la Isla de Cádiz». Al-Andalus, vol. XV, pp. 202-214.

Recibido: 6 de agosto de 2009 Aceptado: 6 de octubre de 2009 